\title{
«LA LIBERTÀ È PARTECIPAZIONE»: LA PARTICIPACIÓN POLÍTICA LOCAL EN ITALIA, ENTRE NORMAS Y REALIDAD
}

\author{
"La libertà è partecipazione": local political participation \\ in Italy, between laws and reality
}

\author{
Ciro Milione \\ Profesor Titular de Derecho Constitucional \\ Facultad de Derecho y CC. EE. y EE. \\ Universidad de Córdoba
}

http://dx.doi.org/10.18543/ed-69(2)-2021pp149-184

Recibido: 10.11 .2021

Aceptado: 13.12.2021

\section{Resumen}

Es común afirmar que la local representa la dimensión política más cercana a la ciudadanía y la más idónea para determinar, en lo cotidiano y en lo colectivo, su bienestar. Esta premisa, sin embargo, puede darse solo si se entienden satisfechos algunos prerrequisitos básicos que atañen tanto a cada ciudadano/a, como a los poderes públicos llamados a administrar la política local, es decir: que exista una voluntad de participar crítica y activamente y que existan las condiciones idóneas, efectivas y reales para lograr esa participación. Este estudio analiza la participación política local en Italia, desde los años ' 70 en adelante, y busca dar respuestas a un fenómeno preocupante y extremadamente actual: el abstencionismo.

\section{Palabras clave}

Italia, política, local, participación, abstencionismo.

\section{Abstract}

It is commonly said that the local policy is the political dimension closest to citizens and the most suitable to determine, on a daily and collective basis, their welfare. 
This premise, however, can only be given on two conditions, which both concern every citizen and the public authorities called to administer local policies: the existence of a willingness to participate critically and actively and the existence of suitable, effective, and real conditions to achieve this participation. This study analyzes local political participation in Italy, from the 1970s onwards, and seeks to provide answers to a worrying and extremely current phenomenon: abstentionism.

\section{Key words}

Italy, policy, local, participation, abstentionism. 


\begin{abstract}
SuMARio: I. Premisa. II. Sobre la EFeCtiva IMPLEMENTACión DEL PRINCIPIO CONSTITUCIONAL DE AUTONOMÍA DE LAS ENTIDADES LOCALES. III. LA EVOLUCIÓN LEGISLATIVA DEL SISTEMA DE PARTICIPACIÓN POLÍTICA LOCAL. 1. La primera fase: la lucha para la participación política local en Italia en los años '70. 2. La segunda fase: autonomía estatutaria municipal y espacios de participación en la Ley 142/1990, de 8 de junio, "Ordinamento degli enti locali» y en el D.Lgs. 267/2000, de 18 de agosto 2000, "Testo unico delle leggi sull'ordinamento degli enti locali». 2.1. Las instancias, peticiones o propuestas. 2.2. Los órganos municipales de consultación: las «consulte». 2.3. Referéndums municipales y otras «formas de consultación». IV. CONSIDERACIONES CONCLUSIVAS: EDUCAR PARA LA PARTICIPACIÓN. V. REFERENCIAS BIBLIOGRÁFICAS EMPLEADAS.
\end{abstract}

«Among all freedoms, that of townships, which is established with such difficulty, is also the most exposed to the invasions of power.»

(Alexis de Tocqueville, Democracy in America, 1835-1840, Vol. I, Part I, Chapter V)

"La libertà non è star sopra un albero, Non è neanche il volo di un moscone, La libertà non è uno spazio libero, Libertà è partecipazione.»

(Giorgio Gaber, La libertà, 1972)

\title{
I. PREMISA
}

Durante los días 3 y 4 de octubre de 2021 cerca de 12 millones de ciudadanos italianos han sido llamados a participar en las elecciones administrativas para la renovación de los órganos representativos de 1192 ayuntamientos. En particular, esta convocatoria ha afectado a 19 capitales de provincia y, además, a 6 capitales de región, con ciudades de gran importancia como Bologna, Milano, Roma, Trieste, Napoli, Torino. Desde el primer día de esa convocatoria los datos del Ministerio del Interior, relativos a la participación parcial, revelaban claramente que un número muy importante de personas llamadas a manifestar su voto estaba renunciando a hacerlo. Esta primera impresión venía a ser corroborada por los datos definitivos que, con un 
$54.6 \%$ de participación total ${ }^{1}$, colocaban el abstencionismo en las elecciones municipales de octubre 2021 en un máximo histórico².

\section{Participación elecciones locales}

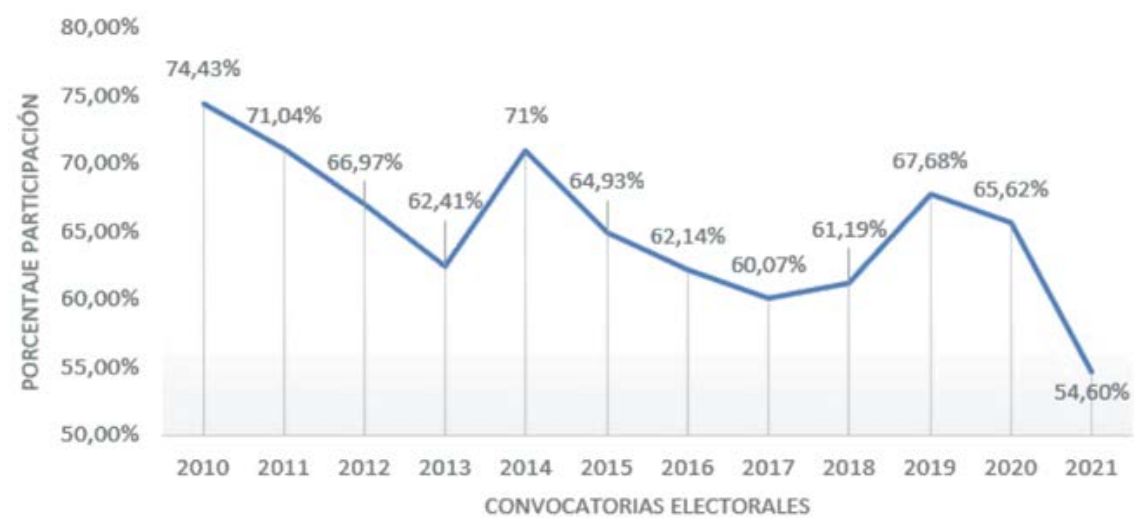

Es frecuente afirmar que la política local constituye la dimensión de la gestión pública más cercana a la ciudadanía. No se trata solo de una cercanía que puede ser «física y real», en la que, dándose las circunstancias, el administrado y el administrador coinciden y conviven diariamente, en un mismo espacio físico y territorial. Se trata en realidad - y sobre todo- de una cercanía que se traduce en la articulación de esos «cauces inmediatos de participación» ${ }^{3}$ que permiten a la ciudadanía constatar, en lo cotidiano, los resultados de sus decisiones políticas y las repercusiones que estas mismas juegan en la consecución del bienestar individual y común. De este modo, cobra vida «desde abajo», desde el nivel más básico de participación, la misma noción de democracia en la que se inspiran nuestros modelos constitucionales ${ }^{4}$.

${ }^{1}$ Cabe señalar que esa misma convocatoria electoral también concernía a la elección del parlamento regional de Calabria y a las elecciones supletivas de la Cámara de los Diputados en la XII circunscripción Toscana y en la XV circunscripción Lazio 1 (Ministero dell'Interno, 2021).

${ }^{2}$ Considérese que el peor dato de participación se había alcanzado en el año 2017, con $60.07 \%$ de afluencia a las urnas con ocasión de la renovación de los órganos representativos de 1004 ayuntamientos (de los que 25 eran capitales de provincia) (Ministero dell'Interno, 2021).

${ }^{3}$ Esta expresión es la que encontramos en el Art. 1 de Ley 7/1985, de 2 de abril, Reguladora de las Bases del Régimen Local, aprobada por el Parlamento español.

${ }^{4}$ La misma Carta Europea de Autonomía Local, aprobada en Estrasburgo (Francia) el 15 de octubre de 1985, por impulso del Consejo de Europa, en su preámbulo 
Sin embargo, la reciente convocatoria electoral italiana, y la tendencia en la que se enmarca, demuestran que algo se ha roto en ese mecanismo complejo, frágil y esencial que es la participación política a nivel local. Este estudio se plantea analizar el estado de esta cuestión desde una perspectiva que examina esas medidas legislativas que el legislador italiano, desde los años 70 en adelante, ha implementado con el fin de permitir y favorecer la implicación de la ciudadanía en la gestión de la cosa pública local.

¿Tiene sentido mirar al pasado para explicar un problema cuya actualidad es incontrovertible?

En opinión de quien escribe estas líneas la respuesta ha de ser positiva. Como veremos más adelante, algunas de las causas del problema radican en decisiones de carácter normativo adoptadas en el pasado por el legislador italiano con el fin de satisfacer - más en las formas que en la sustancia- el mandato constitucional ligado al desarrollo del principio de autonomía de las entidades locales. A estos factores, por otra parte, se unen otros que se han nutrido y han prosperado a la sombra de esas decisiones legislativas equivocadas o ineficaces: la desconfianza de la ciudadanía respecto al hecho político, su apatía, desinterés y desasosiego, todos ellos fruto de una deriva cultural que es necesario detener para dar nueva vida y linfa al sistema democrático italiano.

Por último, este artículo incorpora y amplía algunas de las conclusiones contenidas en la ponencia «Política local y participación ciudadana en Italia» expuesta por el autor en el VII Congreso Internacional «Democracia y Participación Ciudadana», celebrado los días 4 y 5 de octubre de 2021 en la Facultat de Dret de la Universitat de València 5 .

señala que «las entidades locales son uno de los fundamentos de un régimen democrático; $[. .$.$] que el derecho de los ciudadanos a participar en la gestión de los asuntos$ públicos forma parte de los principios democráticos comunes a todos los Estados miembros del Consejo de Europa; [...] que en este nivel local este derecho puede ser ejercido más directamente; [...] que la existencia de Entidades locales investidas de competencias efectivas permite una administración a la vez eficaz y próxima al ciudadano; [...y finalmente] que la defensa y el fortalecimiento de la autonomía local en los diferentes países de Europa representan una contribución esencial en la construcción de una Europa basada en los principios de democracia y descentralización del poder.»

5 Organizado en el marco del Proyecto: «La regulación de la transformación digital y la economía colaborativa. CPI-18-155». Programa Prometeo para grupos de investigación de Excelencia de la Conselleria de Educación, Investigación, Cultura y Deporte de la Generalitat Valenciana y coordinado por el Prof. Lorenzo Cotino Hueso, Catedrático de Derecho Constitucional, y por el Prof. Jorge Castellanos Claramunt, Prof. Ayudante Doctor de Derecho Constitucional, ambos de la Universidad de Valencia. 


\section{SOBRE LA EFECTIVA IMPLEMENTACIÓN DEL PRINCIPIO CONSTITUCIONAL DE AUTONOMÍA DE LAS ENTIDADES LOCALES}

Según el Art. 5 de la Constitución italiana de 1948 (a partir de ahora, más simplemente CI) «La República, una e indivisible, reconoce y promoverá las autonomías locales, efectuará en los servicios que dependan del Estado la más amplia descentralización administrativa y adoptará los principios y métodos de su legislación a las exigencias de la autonomía y de la descentralización».

Esta norma evoca un sistema complejo de niveles de gobierno en el que las entidades locales juegan un papel fundamental, gozando de la facultad de determinar su propio rumbo político y administrativo, en el ejercicio de un derecho a la autonomía que abarca también al ámbito de la financiación. Esta diversificación de niveles se traduce en la posibilidad para la ciudadanía de participar en los procesos políticos de una manera más o menos intensa y cercana a la realidad en la que se desarrolla la vida de cada individuo. Esta misma diversificación, evocada por el Art. 5 CI, cobra sentido concreto en esas formas y límites que la CI dibuja en el Título VI, ahí donde se regulan las entidades locales titulares de ese derecho a la autonomía y que el Art. 114 identifica en los comunes, las provincias, las ciudades metropolitanas y las regiones ${ }^{6}$.

Un análisis histórico - breve- de la norma en cuestión nos puede servir para entender e interpretar en clave actual el sistema de relaciones entre ciudadanía y administración pública, entre ciudadano y entidades llamadas a gestionar la cosa pública local.

Desde esa perspectiva, debemos recordar que, en su momento, la introducción del Art. 5 CI representó para la historia constitucional italiana una auténtica evolución respecto al pasado y la actitud de rechazo del principio de autonomía que había inspirado la acción de los primeros legisladores de

${ }^{6} \mathrm{Y}$, «además», el Estado. Como es sabido, el Art. 114 CI ha sido modificado por efecto de la reforma constitucional implementada por la Ley Constitucional n. ${ }^{\circ} 3 / 2001$, de 18 de octubre, «Modifiche al titolo V della parte seconda della Costituzione» y cuya formulación literal es la siguiente: «La República se compone de municipios, provincias, ciudades metropolitanas, regiones y el Estado.» Sobre el alcance de este precepto se ha pronunciado la Corte Constitucional italiana con la Sentencia (a partir de ahora, SCC) 274/2003, de 24 de julio, en la que ha señalado que al Estado, tras la aprobación de la reforma constitucional, se le sigue reservando una posición peculiar, en el ordenamiento general de la República. Ello se debe, no solo al contenido del Art. 5 CI de la Constitución, que introduce el principio de unidad e indivisibilidad, sino también por la existencia de límites derivados del sistema comunitario y de las obligaciones internacionales, así como de límites inherentes al reparto competencial entre Estado y Regiones (vd. Art. $117 \mathrm{CI}$ ). 
finales del siglo XIX. En efecto, en esa época, una vez lograda la unificación política de la península, no tenía sentido introducir en el sistema jurídico y constitucional motivos o pretextos que pudieran poner en duda una unidad administrativa que - por otra parte - una parte del país consideraba «impuesta»y, de este modo, mermar o debilitar la consolidación de un Estado unitario que, entonces, se acababa de constituir (Benvenuti, 1968, 65 y ss. $)^{7}$.

Así, cuando medio siglo después la asamblea constituyente está llamada a actuar, todavía pervive en una parte de la doctrina y de algunas fuerzas políticas el temor que el reconocimiento del principio de autonomía pueda suponer una debilitación de la República. Finalmente, con el Art. 5 CI prevalecen formalmente las tesis opuestas y, por ende, la autonomía se vuelve expresión de una forma de ser del nuevo modelo constitucional que abandona la configuración de Estado de Derecho unitario para pasar a ser Estado social de las autonomías.

En realidad, la mera aprobación de este precepto no supuso, desde el principio, el despliegue inmediato y completo de todo su potencial jurídico. Debido a los mismos «antiguos temores» de siempre, el legislador, durante los primeros 20 años de vida de la República, dio solo algún tímido paso hacía la realización de un descentralización administrativa efectiva. Se mantenía, en realidad, la lógica del principio jerárquico, de modo que la ampliación de competencias a favor de órganos institucionales de rango inferior al estatal no suponía para ellos la capacidad de adoptar actos definitivos o que no fueran susceptibles de un reexamen o de un control por parte de otra entidad de mayor calado (Lucifredi y Coletti, 1956, 6 y ss.).

Berti (1975a), en relación con esta primera fase de la historia constitucional republicana, habla de una auténtica y «constante lucha para la autonomía» ${ }^{8}$.

7 Por otra parte, Staderini $(1986,37)$ señala que con la aprobación de la Ley municipal y provincial de 1865 el nuevo Estado nacional italiano adoptó un sistema administrativo centralizador de imitación francesa. Se daba vida, de esta forma, a un ordenamiento caracterizado por un poder administrativo central poderoso que, a través del subdelegado del Gobierno (el llamado «Prefetto»), vigilaba sobre la administración local para garantizar que esa cumpliera las directrices y órdenes emanadas por el Gobierno central. En esa segunda mitad del siglo XIX, queda ya lejos el recuerdo del municipio italiano como protagonista del «Risorgimento» y las ideologías que estuvieron a la base de los ordenamientos republicanos de las ciudades italianas que vieron en la autonomía esa capacidad autonormativa fundamentada en el principio «populus est collectio multorum ad iure vivendum quae nisi iure vivat non est populus». Vd. Fenzi, 2020, 60 y 61.

${ }^{8}$ Considérese que los primeros estatutos regionales de tipo «ordinario» empiezan a funcionar solo a partir de los años '70 cuándo, como sostiene Berti, la estructura unitaria del Estado demuestra su insuficiencia y su incapacidad de contrarrestar el anhelo de un mayor espacio de autonomía de la sociedad italiana, (ibidem). 
Una lucha dirigida a lograr «un reconocimiento oficial de la fuerza y de los intereses de los gobernados respecto al gremio gobernante [...una...] lucha para el pluralismo, en el que es implícito el desconocimiento de la solución única y válida para todos presentada por el Estado central $»^{9}$ ( 287 y ss.).

Lejos de ser simplemente reivindicaciones de tipo egoistico o chovinista de supuestos núcleos de poder periférico, esas instancias autonomistas cobran un sentido más amplio y profundo, pues miran a la consecución de una articulación efectiva y de una materialización concreta del principio de autonomía y por ende del principio democrático, hasta sus últimas consecuencias. Porque, como nuevamente señala Berti ${ }^{10}$ «al fondo de la idea de autonomía se halla siempre un principio de autogobierno social y tiene sentido introducir una autonomía en el plano institucional solo en cuanto sea cierto que eso sirva para vivificar la participación social, es decir, hacer efectiva la libertad de los individuos y de los grupos sociales, como presencia activa en la gestión de las administraciones comunes» (1957a, 288).

Se trata de un llamamiento para la defensa de la autonomía que este ilustre jurista realiza desde una tribuna singular (una obra colectiva de gran prestigio) y en un contexto histórico y sociopolítico (mediados de los años '70) que - como veremos a continuación - coincide con uno de los momentos más álgidos del movimiento para el autonomismo local.

Lo que —en nuestra opinión — más destaca en la interpretación que Berti ofrece del Art. 5, es que este autor disecciona la noción de autonomía en dos vertientes distintas, aunque inevitablemente conexas: la que es propia de una autonomía privada que, sin embargo, va declinada en un sentido social; y otra ligada a la idea de una autonomía pública de naturaleza institucional. De modo que, solo cuando se dan las circunstancias para un ejercicio real y efectivo del primer tipo de autonomía, es posible afirmar que el individuo versa en condición de abandonar — si quiere- su condición de súbdito del poder. Pero, para que esas circunstancias puedan darse, es imprescindible que las instituciones autónomas en las que el ciudadano actúa puedan ejercer, real y efectivamente, sus propias atribuciones. Así, autonomía institucional y autonomía individual y social representan las dos caras de una misma moneda, de

9 Salva diversas indicaciones, todas las traducciones del italiano al castellano han sido realizadas por el autor de este trabajo buscando mantener, en la medida de lo posible, el sentido literal del texto original.

${ }^{10} \mathrm{Y}$, antes que él, Tocqueville (1835-40, Cap. V) cuando sostiene que «Es en el municipio donde reside la fuerza de los pueblos libres. Las instituciones municipales son para la libertad lo que las escuelas primarias para la ciencia: la ponen al alcance del pueblo, le hacen gozar de su uso pacífico y le acostumbran a servirse de ella. Sin instituciones municipales, en una nación puede darse un Gobierno libre, pero no tendrá el espíritu de la libertad.» 
una moneda cuyo valor - en último análisis - coincide con el de la democracia y de la libertad, de la solidaridad en lo colectivo y de la responsabilidad en su dimensión individual. En todo eso estriba el contenido del principio de autonomía y su trascendencia para un sistema constitucional que aspire a ser funcional.

Así, para que esos principios puedan materializarse en términos reales, es necesario que las relaciones entre administrados y administradores se realicen en un marco jurídico que favorezca la participación de los primeros en las distintas actividades y competencias tradicionalmente reservadas a los segundos.

Sin embargo, durante los primeros 30 años de vida republicana, esa interpretación evolutiva del Art. 5 CI fue, básicamente, desatendida ${ }^{11}$. Se mantuvo, en cambio, esa lógica de poder más asentada y arraigada en la tradición, una tradición que negaba la posibilidad de una participación de la ciudadanía en los procedimientos administrativos por considerar esa participación superflua e innecesaria, toda vez que las actividades de los poderes públicos se desarrollaran siguiendo los «cauces ineludibles de la ley» (Berti, 1975a, 289).

Esta realidad, trasladada al contexto de la articulación de mecanismos legales que pudieran favorecer la intervención de la ciudadanía en la gestión de la cosa pública local se tradujo esencialmente en una «participación de mínimos», es decir, en la mera aportación, una vez cada 5 años, de una papeleta electoral a una urna, en correspondencia de la celebración de unas elecciones administrativas.

Es necesario tener claros estos puntos de partida porque - cómo veremos a continuación-, a pesar del intenso desarrollo legislativo que ha tenido esta materia en Italia, el modelo de participación política local resultante de cada una de las distintas etapas de ese desarrollo ha fallado en el intento de «lavar algunos de esos pecados originales» del sistema que acabamos de ilustrar.

\section{LA EVOLUCIÓN LEGISLATIVA DEL SISTEMA DE PARTICIPACIÓN POLÍTICA LOCAL}

El lento proceso por el que la política local italiana intenta abrirse a la participación ciudadana en el respeto del sentido más genuino y racional del Art.

${ }^{11}$ Es llamativo que, a mediados de los años 80, Staderini $(1986,43)$ todavía afirmara: "¿Qué es lo que se ha hecho en todos estos años que han seguido la entrada en vigor de la Constitución republicana para dar actuación a los principios consagrados en el Art. 5? Hasta hace no mucho tiempo, la respuesta unánime de la doctrina era "poco o nada"».

Por otra parte, cabría destacar que, más recientemente, Calvano $(2018,3)$ sigue defendiendo que «la historia de esta disposición puede ser narrada [...] como la historia de una larga traición». 
5 CI se articula en dos fases o épocas distintas que podríamos identificar con los años '70 y los años '90. Cada una de estas fases merece ser analizada en profundidad para entender mejor las debilidades del modelo de participación local actual.

\section{La primera fase: la lucha para la participación política local en Italia en los años '70}

Con la Ley 150/1953, de 11 de mayo («Delega legislativa al Governo per l'attribuzione di funzioni statali d'interesse esclusivamente locale alle Provincie, ai Comuni e ad altri Enti»), el Parlamento atribuyó al Gobierno la misión de dar ejecución al Art. 5 CI, transfiriendo funciones estatales de interés exclusivamente local a las Entidades territoriales descritas en el Art. 128 $\mathrm{CI}$ (entonces vigente) ${ }^{12} \mathrm{e}$ incluso a otros órganos descentralizados.

El objetivo - aunque mínimo - de esa delegación legislativa iba encaminado a permitir que esas entidades territoriales pudieran finalmente adoptar actos administrativos definitivos en el ejercicio de sus competencias, en lugar que simplemente intervenir en los procesos de toma de decisión como simples órganos de consultación o respaldo del poder central ${ }^{13}$. Es evidente, pues, cómo en esta fase no pudiera considerarse como suficientemente lograda la implementación del mandato contenido en el Art. 5 CI. Ni que lo

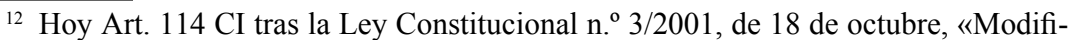
che al titolo V della parte seconda della Costituzione».

${ }_{13}$ Cabe señalar que, de todos modos, los propósitos de la Ley 150/1953 quedaron, en larga parte, desatendidos, pues los dieciséis decretos legislativos que el Gobierno aprobó sirvieron solo para sustraer a la administración central algunas funciones limitadas a materias específicas como turismo, agricultura, comercio, marina mercante, transportes, etc.

Todavía, a principios de los años '60, permanecía sobre la mesa el problema relativo al alcance de la descentralización administrativa del que disfrutarían las entidades territoriales menores, en ejecución del mandato constitucional. Así, por ejemplo, Lucifredi (1960, 247) sintetizaba entonces los términos de la cuestión: «debe considerarse tanto como un problema político de alcance constitucional como un problema técnico. Desde el primer punto de vista, la cuestión está vinculada al dilema constitucional de la autonomía local. Es lógico que deba resolverse de forma diferente según se quiera implantar un sistema de administración rigurosamente uniforme y vinculante en el que los órganos constitucionales sean los únicos que tengan la facultad de dictar directrices para toda la vida del país o si se quiera permitir, dentro de ciertos límites, la libre diferenciación de sistemas y directrices en armonía con las tradiciones, condiciones ambientales y aspiraciones de las distintas partes del territorio nacional. Desde el segundo punto de vista, en cambio, sólo se trata de ver, independientemente de cualquier postulado político, si una buena administración puede obtenerse más a través de un sistema centralizado o descentralizado; es decir, si una administración centralizada o descentralizada es más adecuada para lograr la más rápida y completa satisfacción de las necesidades públicas.» 
fueran las condiciones para una autonomía local auténtica y, por ende, para la introducción de mecanismos locales de participación popular que sirvieran para extender a la ciudadanía la responsabilidad de la gestión de la cosa pública.

Pero más allá de lo que ocurre en el ámbito legislativo, los impulsos más decisivos y consecuentes para lograr mayores espacios de participación en esa gestión, se producen en el contexto social y cultural que vive Italia a principio de los años '70.

Es una fase en el que el país transalpino experimenta, como el resto de las democracias occidentales, los efectos del movimiento del mayo del ' 68 y de ese cambio de paradigmas que este mismo movimiento predicaba. Las críticas -incluso, violentas - que las generaciones más jóvenes de la sociedad dirigen a los esquemas tradicionales, miran a su desmantelamiento y a la creación de espacios de libertad de expresión cultural y política, a la afirmación del pluralismo y de la autonomía, a la promoción de modelos anti-autoritarios. Todo ello se traduce también en reivindicaciones que abarcan al contexto político local y al reconocimiento de un protagonismo nuevo y real del ciudadano en este ámbito de la vida pública y de sus mecanismos de gobierno ${ }^{14}$.

Estas instancias se hacen particularmente fuertes en ciertas partes del país, en esos núcleos urbanos (véase el llamado «triangolo industriale», es decir en las ciudades de Turín, Milán y Genoa) en los que se desarrolla, más que en otros sitios, una auténtica consciencia colectiva, impulsada por actores políticos (sindicatos, movimientos obreros o estudiantiles, etc.) de marcado corte progresista ${ }^{15}$.

${ }^{14}$ Claudio Petruccioli, entonces secretario nacional de la Federación Juvenil Comunista italiana, describiendo la atmosfera del ' 68 y los profundos procesos culturales que investían, en ese periodo, una entera generación y el país en su conjunto, habla de una «explosión de participación política» que se levantaba respecto a una antigua estructura de poder del todo incapaz de encauzar las nuevas reivindicaciones sobre el terreno democrático (Cerchia, 2005, 403).

Es singular también el análisis que realiza Giallongo $(2018,190)$ que, relatando la historia de los movimientos juveniles del ' 68 desde la perspectiva de las «emociones», pone en conexión la felicidad, el bienestar colectivo y la participación como auténtica necesidad, en estos términos: «al abordar esta situación, los miembros del movimiento compartían la idea de que el bienestar de todos germinaría por la confluencia de la política en la vida cotidiana. Se inspiraron así en la idea de Revolución del siglo XVIII, convencidos idealmente de que la felicidad no era un privilegio personal o de clase, sino una experiencia colectiva. Probablemente fue en esta perspectiva en la que la participación individual en la vida pública se vivió como una experiencia singular e insustituible de felicidad humana.»

${ }^{15}$ En algunas partes del país, adquiere carácter de urgencia la creación de cauces reales de participación que sirvan para responder a las instancias presentadas por parte de la población con ímpetu y pasión. Es lo que es posible deducir de las palabras de dos administradores de la Democracia Cristiana a cargo, en esa época, de distintos departamen- 
Las reivindicaciones en esa fase histórica son fundamentalmente las que atañen a cuestiones muy concretas y ligadas a la realidad cotidiana: como la vida asociativa en el barrio, la vivienda, los servicios colectivos, etc. Es importante considerar el ámbito en el que se producen estas instancias: nos hallamos en un contexto socioeconómico en que confluyen en las ciudades (particularmente del norte de Italia) un gran número de migrantes provenientes de las regiones del sur. Es una población con características culturales y sociológicas radicalmente diversas respecto a las de los centros urbanos a los que se mudan y en los que trabajan. Así, lentamente, dentro de estas grandes ciudades que experimentan el boom industrial, toman vida barrios - generalmente, periféricos - que, aun formando parte de la administración local, constituyen desde un punto de vista identitario y cultural, realidades auténticamente separadas de su entorno ${ }^{16}$.

La administración local, con sus órganos, instituciones, procedimientos etc., es percibida como una entidad ajena y alejada - incluso físicamentede las necesidades de esta parte de la población que más precisa de la intervención de los poderes públicos. Este gap representativo exige respuestas orgánicas y coordenadas. Por ello, algunas administraciones particularmente sensibles al fenómeno que acabamos de describir deciden crean, en las medidas de sus posibilidades, improvisados órganos de descentralización administrativa. Lo hacen a través de expedientes normativos que invocan normas preconstitucionales ${ }^{17}$ que permiten a sujetos delegados ejercer algunas funciones propias de los alcaldes.

tos del ayuntamiento de Torino: «los grupos espontáneos, que se definen comités de barrio, nos los encontramos ya cada día en el ayuntamiento o en los distintos lugares objeto de ocupación (escuelas, parques, viviendas de protección oficial) y tenemos que contratar con ellos sin saber de qué representatividad realmente gozan o si, sin embargo, no constituyen nada más que la expresión de pequeñas minorías.» (Staderini, 1986, 67).

${ }^{16}$ Considérese, por ejemplo, la realidad de la ciudad de Torino. La capital de Piemonte en 1953 contaba con 753.000 habitantes y pasó a tener 1.114.000 en 1963. La mayoría de esas personas habían emigrado de Sicilia (77.589), Puglia (106.413), Calabria (44.723), Campania (35.489) o Basilicata (22.813). Su presencia se concentraba en contextos urbanos definidos como el barrio de la «Barriera di Milano». Su proceso de integración fue difícil, como demuestran estas palabras: «La llegada a la ciudad conlleva problemas y dificultades que no son fáciles de superar. Las diferencias culturales e identitarias transforman el encuentro entre los turineses y los inmigrantes, sobre todo los del sur, en un momento de gran tensión. La discriminación adopta la forma de carteles colocados en las puertas de las casas con la frase 'no se alquila a meridionales' o se traduce en dinámicas excluyentes que pasan por epítetos llenos de odio ('napuli', 'terroni', 'mau mau'), palabras acuñadas por la población local para definir, identificar, desacreditar y burlarse de los obreros nativos de esas regiones del sur.» (ISMEL, s.f., 12).

17 Un ejemplo son los Arts. 154 y 155 del Texto Único de la Ley municipal y provincial de 1915 (R.D. 148/1915, de 4 de febrero) por los que, los municipios con más de 
Es en esta época en la que empiezan a funcionar órganos llamados «Consigli di quartiere» (literalmente, «consejos de barrio») y el «Aggiunto del Sindaco» («el adjunto del alcalde») en ciudades con una profunda tradición progresista y de izquierda como Bolonia ${ }^{18}$. Sin embargo, es oportuno señalar que - en particular - las labores de los consejos de barrio no excedieron nunca el mero desarrollo de actividades propositivas o consultivas ${ }^{19}$ en relación con actos de mayor importancia (la presentación de los presupuestos, la elaboración de programas de desarrollo o de los planes reguladores) (Staderini, 1986, 69).

60.000 habitantes podían deliberar de ser divididos en barrios. En esos supuestos, el alcalde podía decidir, previa aprobación del prefecto, la delega del ejercicio de sus funciones. Igualmente, en los barrios o distritos que dispusieran de un patrimonio o de gastos separados, podían actuar delegados del alcalde nombrados por él y aprobados por el prefecto. Vd. a este respecto Berti que consideró estas iniciativas como auténticos experimentos encaminados a reanudar la tradición del derecho municipal y a reivindicar la capacidad estatutaria de los ayuntamientos y de normación de los barrios (1975b, 68).

${ }^{18} \mathrm{Su}$ funcionamiento era, grosso modo, el siguiente: el adjunto presidía el consejo de barrio, desarrollando algunas funciones propias del alcalde y dirigiendo órganos municipales descentralizados. Los consejos de barrio estaban constituidos por residentes o trabajadores de un determinado territorio municipal. Habían sido nombrados por el pleno del ayuntamiento, según criterios de representación proporcional que reflejaban el peso distinto de los diversos grupos políticos elegidos en su seno. Vd. Zacchini, Bruna. 1976. Dieci anni di decentramento a Bologna. Bologna: Edizioni Luigi Parma; y también Ceccarelli, Francesco y Maria Angiola Gallingani. 1987. Bologna: decentramento, quartieri, città 1945-1974. Bologna: Istituto per la storia di Bologna.

${ }^{19}$ Es oportuno recordar, como hace Barresi $(1994,1158)$, que existe una gran diferencia entre las nociones de «participación» y «consultación»: en la primera la responsabilidad por un acto o decisión recae en todos los sujetos que han intervenido y participado en el procedimiento; en la segunda, esa responsabilidad es exclusivamente imputable al órgano público que, en un ejercicio de discrecionalidad política, puede hacer suyas las opiniones de los consultados, o no hacerlo. Una tercera noción por considerar sería la de «contradictorio», es decir, una garantía a favor de las partes, llamadas a defender en igualdad de condiciones unos intereses distintos, potencialmente en conflicto entre sí.

Vandelli $(2015,227)$, sin embargo, habla de dos tipos distintos de participación: la de tipo «decisorio», en la que la ciudadanía está llamada a adoptar decisiones finales (ej. «presupuestos participativos» o los «referéndums abrogativos»); y la de tipo «colaborativo», en la que la implicación ciudadana se desarrolla en el ámbito de un procedimiento que se concluye, de todos modos, con una decisión adoptada por los órganos políticosadministrativos.

Por otra parte, cabe matizar la distinción entre «instrumentos de participación popular o institucional» que son mecanismos a través de los que se articula la democracia directa (por ej., los referéndums), encontrando su regulación en la ley y produciendo efectos que inciden en las instituciones; y los «instrumentos informales de participación», iniciativas a través de las que la población promueve y defiende sus intereses a través de asambleas, manifestaciones, etc. (Vd. Luciani, 2008, 163). 
Estas experiencias constituyeron un primer paso hacia la descentralización y hacia la creación de mecanismos de representación popular que sirvieran para acercar la política local a la ciudadanía. Lo cierto es que estos mismos intentos, huérfanos de una fundamentación normativa sólida, no podían aspirar a tener una vida que fuera larga y próspera ${ }^{20}$.

Esta fundamentación finalmente se produjo con la Ley 278/1976, de 9 de abril, «Norme sul decentramento e sulla partecipazione dei cittadini nell'amministrazione del comune», que formalmente instituyó los así llamados «consigli di circoscrizione». Se trataba de órganos con naturaleza democrática y con carácter deliberativo y de gestión, cuya función esencial no era solo la de incrementar e intensificar la representatividad de la población en los órganos de gobierno municipal, sino particularmente la de contrarrestar o compensar el poder de la clase política local, por ejemplo, a través de la adopción de resoluciones que los plenos municipales podrían ignorar solo asumiendo el correspondiente coste político ante la ciudadanía ${ }^{21}$.

El Art. 15 de la ley, además, introducía para los electores del municipio la posibilidad de presentar peticiones al ayuntamiento para «la promoción de la descentralización» y peticiones y propuestas a los respectivos consejos en materias que fueran de su competencia. La condición en ambos casos es que esas mociones fuesen respaldadas al menos por un décimo de los votantes de la circunscripción.

${ }^{20} \mathrm{Y}$, en efecto, por ejemplo, el Tribunal Administrativo Regional de Piemonte, pronto declaró «inexistente», por falta de competencias en mérito, el reglamento municipal de Torino relativo a la institución y al funcionamiento de los consejos de barrio (sentencia 128/1975, de 25 de junio). Igualmente, el Consejo de Estado dictaminó que no sería admisible la creación, por iniciativa de los ayuntamientos, de órganos especiales de descentralización cuando esos no fueran previstos en la legislación (dictamen 2242/1975, de 31 de octubre). Cabe señalar, como hace Pastori (1962, 547-8), que durante un largo periodo de tiempo los jueces administrativos trataron las normas constitucionales sobre la autonomía local como preceptos con «eficacia diferida», a considerar exclusivamente como cánones hermenéuticos en la labor interpretativa de las normas ordinarias.

${ }^{21}$ El Art. 2 de la Ley establecía que los órganos de la circunscripción serían el Consejo, llamado a representar las exigencias de la población en la circunscripción, y el Presidente del Consejo, llamado a representarlo y a desarrollar las funciones delegadas por el alcalde. Dichos consejos tenían carácter democrático, siendo sus miembros elegidos por sufragio directo de los residentes en la circunscripción (Art. 3) con reparto de escaños según criterios proporcionales (Art. 6). La duración de su mandato coincidía con la del ayuntamiento. La labor de los consejeros (gratuita, según lo establecido por el Art. 17) consistía en el desarrollo de funciones consultivas (algunas) o deliberativas (escasas), todas ellas recogidas en el Art. 12. Entre ellas destacaríamos: la aprobación de informes sobre la gestión de bienes, servicios e instituciones; la posibilidad de convocar asambleas públicas; la presentación de propuestas para la solución de problemas administrativos; la producción de dictámenes sobre materias de competencia del ayuntamiento. 
La realidad demostró, en un plazo relativamente breve de tiempo, que la Ley 278/1976 y sus instrumentos de participación resolvían poco y mal aquellos problemas que habían determinado, en primer lugar, su aprobación. Asimismo, resultó evidente que la norma había encontrado escasa aplicación en todo el territorio nacional, con la salvedad de algunas raras y loables excepciones en Piemonte, Emilia Romagna, Lazio, etc.

Las razones de ese fracaso son de naturaleza diversa.

En primer lugar, cabría hacer hincapié en el carácter provisional de la Ley 278/1976, puesto en evidencia por su Art. 1, en el que se señalaba - de una manera, por otra parte, obvia - que la normativa se mantendría válida hasta la entrada en vigor de un futuro ordenamiento de las autonomías locales.

En segundo lugar - entrando ya en el fondo de la cuestión - el funcionamiento real de los consejos de circunscripción hizo evidente que los dictámenes aprobados por los mismos —en determinados casos obligatorios, pero casi nunca vinculantes - acababan sistemáticamente siendo ignorados por los órganos municipales que asumían de buen grado el coste político asociado a decisiones contrarias a los dictámenes de esos órganos representativos. Lo mismo ocurría con las deliberaciones que, en virtud del Art. 14, debían ser remitidas a los plenos de los ayuntamientos para la realización de un examen de fondo que cerraba el expediente.

En tercer lugar, pese a lo señalado con anterioridad, era bastante insólito que los consejos de circunscripción entraran en conflicto con los ayuntamientos o realizaran alguna oposición realmente provechosa para la ciudadanía. Eso mismo ocurría porque el sistema permitía que los partidos políticos siguieran teniendo un peso decisivo en la designación de los candidatos a formar parte de esos consejos ${ }^{22}$. De esta forma, esos órganos acababan reflejando los equilibrios y las dinámicas políticas ya presentes en las asambleas municipales y muy frecuentemente las decisiones de los consejos de circunscripción venían adoptadas según lógicas que primaban el interés sectario y el respeto a la disciplina de partido. En un contexto como el que acabamos de indicar, no nos debe sorprender si los intereses reales de la ciudadanía residente en el territorio representado acabaran teniendo, en seno a esos órganos, un peso meramente residual.

Por último, los instrumentos de participación popular — peticiones, propuestas, etc. - tal vez útiles en municipios de escasas dimensiones ${ }^{23}$, exigían

${ }^{22}$ Considérese que a la luz del Art. 5 de la Ley 3/1978, de 3 de enero, («Norme per l'effettuazione delle elezioni provinciali e comunali») se estableció el principio de simultaneidad de las elecciones de los consejos de circunscripción con las elecciones municipales y provinciales, algo que determinó una definitiva influencia de los partidos en esos órganos de reciente constitución.

${ }^{23}$ Staderini resume la cuestión en estos términos: «de participación es posible hablar solo en relación con pequeños barrios, donde efectivamente pueden existir vínculos de 
sin embargo la movilización de un gran número de votantes para la recogida de avales en las circunscripciones de grandes ciudades: un esfuerzo que se revelaba, de todos modos, inútil a la luz del monopolio partidista que caracterizaba las dinámicas políticas de los consejos de circunscripción.

Estas consideraciones nos permiten realizar algunas reflexiones de carácter preliminar. Es evidente que ya en esa época el problema de la realización de la descentralización administrativa y de la implementación de instrumentos de participación en la política local no constituían simplemente cuestiones de técnica jurídica, ligadas a la necesidad de dar ejecución a uno de los numerosos mandatos constitucionales. Los contornos del problema eran -y siguen siendo hoy - más amplios y decisivos como siempre ocurre cuando la cuestión a debatir es la que atañe al ejercicio monopolístico del poder y a su gestión efectiva en un ámbito territorial definido, como es el caso que nos interesa.

Si el propósito de la Ley 278/1976 consistía en la realización de una descentralización administrativa que acercara la gestión de la cosa pública local al ciudadano, el resultado finalmente logrado fue otro: la creación de unos órganos de participación que lo fueron solo formalmente, mientras los mismos actores políticos de siempre volvían a ocupar esos espacios mínimos de influencia que la norma había imaginado, en primer lugar, para la ciudadanía más comprometida.

El ejemplo de la Ley 278/1976, desde esta perspectiva, vino a anticipar dinámicas y errores de los que - como veremos - el legislador italiano no supo o no quiso librarse: identificar la descentralización con la participación; no ser capaz de preservar a favor de la ciudadanía espacios nuevos de participación y, sobre todo, confundir la mera aprobación de una norma jurídica con la efectiva consecución de cambios en la realidad social y política de una comunidad.

\section{La segunda fase: autonomía estatutaria municipal y espacios de} participación en la Ley 142/1990, de 8 de junio, «Ordinamento degli enti locali» y en el D.Lgs. 267/2000, de 18 de agosto 2000, "Testo unico delle leggi sull'ordinamento degli enti locali»

Como hemos señalado, la Ley 278/1976 nació con vocación de perdurar en el tiempo lo estrictamente necesario para que el legislador italiano pudiera aprobar una más orgánica regulación del derecho de las entidades locales. Esa esperada regulación tardó catorce años en ver la luz con la entrada en vigor de la Ley 142/1990, de 8 de junio, «Ordinamento degli enti locali».

solidaridad entre los habitantes y la conciencia de pertenecer a una misma comunidad. Cuando una comunidad se encuentra al alcance de la mano [...] es más fácil hacer oír la propia opinión y es más fuerte el estímulo a hacerlo» $(1985,75)$. 
Siguiendo a Vesperini (2010, 954-960) es posible identificar cuatro razones diversas que contribuyeron, de alguna manera, a desbloquear el impasse.

En primer lugar, al comienzo de los años 90, los actores políticos italianos manifestaron su clara voluntad de dar vida a un periodo de profundas reformas legislativas que afectaran a diversos sectores del Derecho Administrativo ${ }^{24}$. Así, finalmente, se procuró dar ejecución al dictado constitucional en materia administrativa de una manera que fuese más completa, efectiva y respetuosa de importantes principios como el de autonomía y de policentrismo. En este sentido, Vesperini defiende que la nueva regulación de las entidades locales actuó como una verdadera «cabeza de puente» («apripista», en el texto original) llamada a ser la premisa para una reforma más orgánica y extendida de todas las demás administraciones públicas (956).

En segundo lugar, la reforma introducida por la Ley 142/1990 vino a ser un banco de prueba «a pequeña escala» de las innovaciones a introducir en el caso de una posible remodelación del sistema político en su totalidad. Se trataba de testar mecanismos dirigidos a atacar, antes que nada, el atávico problema de la inestabilidad política y a reducir, en la medida de lo posible, el excesivo protagonismo de los partidos en todos los ámbitos de participación ${ }^{25}$.

La tercera razón, sin embargo, ligaba el destino de los municipios y de las provincias al de las regiones. Efectivamente, incluso para estas últimas, la disciplina vigente con anterioridad a la reforma de 1990 constituía un auténtico estorbo en el camino hacia una efectiva distribución territorial del poder. Es posible entender la razón de ello mirando a la disposición transitoria VIII

${ }^{24}$ No olvide el/la lector/a que es de este mismo periodo la importante Ley 241/1990, de 7 de agosto, «Nuove norme in materia di procedimento amministrativo e di diritto di accesso ai documenti amministrativi», que ha supuesto un notable salto en adelante para el derecho administrativo italiano introduciendo, entre otros aspectos, la obligatoriedad de la motivación de los actos administrativos; una nueva disciplina del silencio administrativo; la existencia de intereses legítimos colectivos; etc. Vd., entre otros, Pinto, Ferdinando. 2017. «La disciplina del procedimento amministrativo a quasi trent'anni dall'approvazione della Legge n. 241 del 1990». Amministrativamente. Rivista trimestrale di diritto amministrativo, n. ${ }^{\circ}$ 11-12; Patroni Griffi, Giuseppe. 2011. «Procedimento amministrativo e responsabilizzazione dei poteri pubblici: a vent'anni dalla legge n. 241/1990». Corriere giuridico, Vol. 28 - n. ${ }^{\circ}$ 3: 301-309; Scafoletti, Marcella. 2004. «Appunti sulla legge di riforma del procedimento amministrativo 7.8.1990, n. 241 e successive modifiche». Il nuovo diritto, Vol. 81 - n. ${ }^{\circ} 11$; Resta, Domenico. 1992. «Il 'vero' volto della riforma del procedimento amministrativo attuato ai sensi della legge 7 agosto 1990 n. 241». Rivista amministrativa della Repubblica Italiana, Vol. 143 — n. ${ }^{\circ}$ 10: 1407-1416.

${ }_{25}$ En efecto, la Ley 142/1990 fue el preludio para la aprobación sucesiva de la Ley 81/1993, de 25 de marzo, «Elezione diretta del sindaco, del presidente della provincia, del consiglio comunale e del consiglio provinciale» que, como la misma rúbrica indica, permitió, entre otras cosas, la elección directa del alcalde e introdujo mecanismos de control político en los ayuntamientos como, por ejemplo, la moción de censura constructiva. 
de la CI por la que la restructuración y el reparto de las funciones administrativas entre las entidades locales es condición para que las Regiones puedan entrar a disciplinar legalmente las funciones de las respectivas provincias y ayuntamientos.

La cuarta y última razón miraba más allá de las fronteras nacionales. En efecto, no debemos olvidar que solo un año antes de la entrada en vigor de la reforma, Italia había aprobado la Carta Europea de Autonomía Local, obligándose formalmente a la implementación de principios fundamentales como los de electividad (Art. 3.2), de subsidiariedad (Art. 4.2), de autonomía organizativa (Art. 6) y financiera (Art. 9), y de plenitud de las competencias encomendadas a las Entidades locales (Art. 4.4), todos principios ${ }^{26}$ que la misma Ley 142/1990 acabaría haciendo suyos ${ }^{27}$.

La reforma, como es obvio, fue de gran alcance y tocó — con más o menos fortuna- ámbitos distintos de la autonomía local. En lo que nos atañe - la introducción de cauces de participación ciudadana en la gestión política local- la innovación más relevante fue la relativa a la regulación de la autonomía estatutaria municipal (Art. 4) y a la aprobación de un título («Capo III. Istituti di partecipazione») integralmente dedicado a la introducción de mecanismos de participación (Arts. 6-8) 28 $^{28}$ que pasaban a ser previstos como obligatorios en los estatutos municipales.

Así, el Art. 4 establecía claramente que municipios y provincias adoptarían, cada uno, sus estatutos para determinar las normas fundamentales relativas a sus respectivas competencias, a su organización interna y a la de sus servicios. Además, el segundo apartado de este mismo precepto establecía

${ }^{26}$ Sobre la Carta Europea de Autonomía Local y sus principios señalamos, entre otros, Lasagabaster Herrarte, Iñaki. 2007. La carta europea de la autonomía local. Madrid: Iustel; Ortega Álvarez, Luis Ignacio. 1993. «La Carta Europea de la autonomía local y el ordenamiento local español». Revista de estudios de la administración local y autonómica, n. ${ }^{\circ}$ 259: 475-498; Ferreira Fernández, Antonio Javier. 2016. «La Carta Europea de Autonomía Local: orígenes y perspectivas». Dereito: Revista xuridica da Universidade de Santiago de Compostela, n. ${ }^{\circ}$ Extra 1: 13-20; Merloni, Francesco. 2010. «La Carta Europea de la Autonomía local y su recepción en Italia y España». Anuario del Gobierno Local, n. ${ }^{\circ}$ 1: 489-519.

${ }^{27}$ Por otra parte, la aprobación del Tratado de Maastricht exigía a cada Estado miembro la adopción de medidas legislativas para implementar esos mismos principios de descentralización, siendo las regiones y las demás entidades locales sujetos destinatarios de las nuevas políticas comunitarias (Vesperini, 2010, 959-960).

${ }_{28}$ Merece la pena volver a recordar lo que ya señalamos en la nota $\mathrm{n}^{\circ}{ }^{\mathrm{o}} 18$, es decir, que el concepto de «participación» es algo distinto respecto a los de «consultación» o de «contradictorio». Sin embargo, es significativo que este título de la Ley 142/1990 agregara instrumentos distintos, por naturaleza y funciones, en un mismo contexto. Para Barresi (1994, 1158) la razón de ello residía en que todos esos recursos concurrían a la determinación de intereses colectivos, en una «síntesis de dimensión social y dimensión personal». 
que los estatutos recogerían «las formas [...] de la participación popular, de la descentralización, del acceso de los ciudadanos a las informaciones y a los procedimientos administrativos».

El Art. 6, sin embargo, entraba más en profundidad en la cuestión participativa determinando para los ayuntamientos la obligación de «valorizar las formas asociativas libres» de ciudadanos y la de promover su participación en la administración local. El segundo apartado de este precepto establecía la necesidad de que las normas fundamentales de funcionamiento de esas entidades locales incluyeran la posibilidad, para las personas interesadas, de intervenir en los procedimientos que desembocaran en la adopción de actos que pudieran repercutir en sus situaciones jurídicas subjetivas. El tercer apartado hacía preceptivo que los estatutos previeran formas de consultación de la población y además procedimientos para la presentación, por parte de particulares o asociaciones ciudadanas, de instancias, peticiones o propuestas. Además, la norma establecía la necesidad de que se adoptaran garantías para asegurar el rápido examen de esas mociones. Por último, el Art. 6.3 reconocía la posibilidad para los ayuntamientos de determinar, en sus estatutos, instrumentos refrendarios con fines consultivos.

El panorama de los instrumentos participativos descritos en el citado título III de la Ley 124/1990 se completaba con la introducción de la acción popular (Art. 7.1: «cada elector puede actuar ante las jurisdicciones administrativas para hacer vales las acciones y recursos que competen al ayuntamiento»); con el reconocimiento del derecho de los ciudadanos de acceder a los actos de la administración municipal (Art. 7.3) ${ }^{29}$; y, finalmente, con la posibilidad para los ayuntamientos y las provincias de establecer un defensor ciudadano (Art. 8) como «garante de la imparcialidad y del buen funcionamiento de la administración pública municipal o provincial», llamado a informar sobre los abusos, disfunciones, deficiencias y retrasos de la administración hacia los ciudadanos ${ }^{30}$.

${ }^{29}$ Con algunas salvedades. En efecto, el Art. 7.3 excluía el acceso a los actos reservados por «indicación expresa de la ley o como resultado de una declaración temporal y razonada del alcalde [...] que sirva para prohibir su publicación, de acuerdo con las disposiciones reglamentarias, cuando su difusión pueda ser perjudicial para el derecho a la intimidad de las personas, de grupos o empresas.» Cabe destacar que esta norma supuso una inversión de 180 grados respecto al pasado, es decir, respecto al principio por el que el secreto administrativo constituía una regla ligada a la naturaleza del sujeto llamado a custodiar el documento o el dato. El Art. 7 de la Ley 124/1990 estableció el exacto contrario: la transparencia es la norma y el secreto una excepción a justificar sobre la base del contenido de la información. Vd. (Giusepponi, 2009, 156).

${ }^{30}$ En la práctica, el defensor cívico ha dejado de existir por efecto del Art. 2.186.a) de la Ley 191/2009, de 23 de diciembre («Disposizioni per la formazione del bilancio annuale e pluriennale dello Stato»), «víctima» de los recortes económicos y de la implementa- 
A lo largo de su vigencia la Ley 142/1990 fue sometida a 23 reformas que afectaron partes relevantes de su articulado. Sin embargo, es llamativo que la única enmienda relativa a la materia participativa, fue la que determinó el Art. 3.1 de la Ley 265/1999, de 3 de agosto, «Disposizioni in materia di autonomia e ordinamento degli enti locali, nonche' modifiche alla legge 8 giugno 1990, n. 142» y que afectó al Art. 6.1 de la Ley 142/1990, modificándolo en mínima parte, es decir, sustituyendo la expresión «participación de los ciudadanos» con la fórmula "participación popular» y eliminando la referencia a la función «consultiva» de los referéndum locales.

Fuere como fuere, el título III de la Ley 142/1990 acabó por confluir casi integralmente en la parte final (Arts. 8-11) del título I («disposizioni generali») del D.Lgs. 267/2000, de 18 de agosto, «Testo unico delle leggi sull'ordinamento degli enti locali» (a partir de ahora, TUEL) actualmente vigente, que vino a abrogar por completo la reforma de 1990.

Los cambios legislativos introducidos por el TUEL y concernientes a la participación ciudadana en la política local han sido diversos ${ }^{31}$. Sin embargo, uno de los aspectos más novedosos, relacionado con esta misma materia y con la descentralización administrativa, ha sido el que se halla contenido en el Art. 17 TUEL que, en parte, retoma y modifica el Art. 13 de la Ley 142/1990 en materia de circunscripciones de descentralización municipal. Así, al día de

ción del principio de equilibrio presupuestario. De todos modos, como señala Vandelli $(2015,240)$, durante los años de su existencia esa institución ha sido fuertemente criticada incluso desde la perspectiva de la simplificación administrativa. Hoy en día sobrevive la figura del «defensor cívico territorial», cuyas competencias se desarrollan a nivel provincial y, en otros casos, la del defensor regional.

${ }^{31}$ Esos cambios han consistido, en primer lugar, en la sustitución de la expresión «participación de los ciudadanos» (Art. 6.1 de la Ley 142/1990) con la fórmula «participación popular» en el Art. 8 TUEL. Esa enmienda, que desvincula la participación de la condición de gozar de ciudadanía, se explica a la luz del quinto apartado de ese mismo precepto, por el que los estatutos municipales deben promover «formas de participación en la vida pública local de ciudadanos de la Unión Europea y extranjeros con residencia legal».

Asimismo, el segundo apartado del Art. 8 TUEL hoy establece que, en los procedimientos que desemboquen en la adopción de actos que puedan incidir en situaciones jurídicas subjetivas, deben estar previstas formas de participación de los interesados que respondan a los principios consagrados en la Ley 241/1990, de 7 de agosto.

El tercer apartado del Art. 8 TUEL, por su parte, elimina la referencia a la exclusiva naturaleza consultiva de los referéndums que pueden constituir un «contenido eventual» de los estatutos municipales.

El Art. 9 TUEL (correspondiente en parte al Art. 7 de la Ley 142/1990) hoy día permite a cada elector actuar en juicio, ante cualquier jurisdicción —no solo la administrativa-, para las acciones y recursos que correspondan al ayuntamiento o a la provincia.

Por último, un precepto aparte, el Art. 10, establece el «Derecho de acceso e información». 
hoy $^{32}$, «los municipios con una población de más de 250.000 habitantes disponen de la posibilidad de dividir su territorio en distritos con una población media no inferior a 30.000 habitantes», mientras que los municipios con más de 300.000 habitantes pueden prever en sus estatutos «formas particulares y más acentuadas de descentralización [...] determinando además [...] los órganos de esas formas de descentralización, los estatus de sus miembros y las relativas formas de elección, nombramiento y designación.» (Art. 5).

Esas previsiones normativas, en la práctica, han sido transpuestas en los estatutos municipales en una pluralidad de instrumentos participativos descritos y regulados de modo variado que, desde un punto de vista subjetivo (Vandelli, 2015, 226 y 227), pueden involucrar a sujetos titulares de derechos o intereses legítimos ${ }^{33}$, «sujetos colectivos ${ }^{34} \mathrm{o}$ «sujetos residentes» ${ }^{35}$. Desde esta misma perspectiva, el Art. 8 TUEL hace alusión, por un lado, a unas «formas asociativas libres» y, por otro, a unos «organismos de participación popular» cuya acción deben ser «valorizadas» (literalmente) por los ayuntamientos. Siguiendo a Rolla, Groppi y Luatti $(1990,69)$ las «formas» corresponderían a personas jurídicas de derecho privado, análogas a las «formaciones sociales» de las que habla el Art. 2 CI. De este modo, su característica sería la de surgir en el tejido social de forma espontánea para dialogar libremente (es decir, sin injerencias ajenas) con los poderes públicos locales llamados a reconocerlas y legitimarlas como sujetos y, a la vez, instrumentos de participación. Sin embargo, el origen de los «organismos de participación popular» se hallaría en esos mismos poderes públicos locales que, en el ejercicio de su autonomía estatutaria, pueden regular su funcionamiento y su organización interna.

${ }^{32}$ Es decir, tras la reforma de ese precepto que ha producido el Art. 2.186.b) de la Ley 191/2009, de 23 de diciembre, modificada a su vez por el D.L. 2/2010, de 25 de enero, convertido con modificaciones por la Ley 42/2010, de 26 de marzo.

33 En cuyo caso hablaremos de una participación de tipo administrativo dirigida a garantizar la preservación de situaciones jurídicas subjetivas en procedimientos puntuales que, concerniendo a individuos determinados, permite su intervención para la defensa de sus propios intereses.

${ }_{34}$ Se trata de la intervención de actores que, por su propia naturaleza, se consideran portadores de intereses colectivos (por ej. sindicatos) o de intereses difusos (asociaciones ambientalistas, etc.) véase, por ejemplo, el citado Art. 9 del D.Lgs. 267/2000.

35 En efecto, en los supuestos descritos por el Art. 8 TUEL, es más correcto vincular la participación de un particular a su condición de residente en lugar que a su nacionalidad. Eso se debe no solo al contenido del ya citado Art. 8.5 TUEL, sino también en virtud de lo que establece el Art. 2 del D.Lgs. 286/1998, de 25 de julio, «Testo unico delle disposizioni concernenti la disciplina dell'immigrazione e norme sulla condizione dello straniero»; y la Ley 203/1994, de 8 de marzo, por la que se ratifica y se da ejecución al Convenio sobre la participación de los extranjeros en la vida pública a nivel local (firmada en Estrasburgo el 5 de febrero de 1992). 
Entre todos los mecanismos - facultativos u obligatorios- que el TUEL introduce para promover la participación ciudadana en la política local italiana, destacan las instancias, peticiones o propuestas, unos órganos de consultación definidos «consulte» y los referéndums recogidos en el tercer y cuarto apartado del Art. 8. A continuación, pasamos brevemente a describirlos.

\subsection{Las instancias, peticiones o propuestas}

Según establece el Art. 8.3 TUEL en el «estatuto (municipal) deben estar previstas [...] formas para la admisión de instancias, peticiones y propuestas de ciudadanos particulares o asociados dirigidas a promover una mejor tutela de los intereses colectivos y deben estar, además, determinadas las garantías para su rápido examen.»

El precepto pone de manifiesto que esos instrumentos constituyen un contenido obligatorio para todas las normas fundamentales que regulan el funcionamiento de los ayuntamientos italianos. Y no obstante resultan dudosas las diferencias existentes entre las tres categorías de mecanismos indicados, algunos (por ej. Conte, 2015, 77 y 78) consideran posible afirmar que una «instancia» debería cumplir la función de requerir una intervención por parte de la administración municipal sobre situaciones que atañen a ciudadanos determinados o intereses de naturaleza individual. Una «petición», sin embargo, concerniría a individuos o asociaciones que plantean un problema social o colectivo y solicitan con urgencia la atención de los órganos políticos locales, sin especificar los detalles de la intervención requerida. En el caso de las «propuestas», sin embargo, la ciudadanía formula iniciativas que se caracterizarían por un contenido más detallado y que simplemente requieren una deliberación al respecto por parte de las autoridades locales.

Más allá de esta reconstrucción interpretativa, debemos destacar que la reglamentación final de cada uno de estos instrumentos recae en la disponibilidad de los ayuntamientos que los disciplinan en sus respectivos estatutos como mejor estimen, en el ejercicio de su propio derecho a la autonomía. Así, a título meramente ejemplificativo, los Arts. 3 y 4 del «Regolamento sui diritti di partecipazione e di informazione dei cittadini» del ayuntamiento de Bologna (Iperbole, 2021a) establecen, respectivamente, que las instancias son solicitudes de información dirigidas a cualquier administración municipal, presentadas por escrito y con indicación del solicitante, que el órgano competente debe resolver en un plazo inferior a 30 días, incluso «informalmente» a través de coloquio verbal o telefónico. En lo que atañe a las peticiones, el Art. 4 del citado «Regolamento» establece que deben ser presentadas por 300 «personas» ( $\mathrm{sic}$ ), identificadas oportunamente, y que deben ser protocolizadas por la Secretaría General del ayuntamiento. Las respuestas del alcalde o del concejal competente o del presidente del pleno municipal deben 
darse por escrito en un plazo no superior a los 3 meses y deben ser incluidas en un archivo público custodiado por la misma Secretaría general. Por último, el Art. 5 del «Regolamento» disciplina el ejercicio del derecho de iniciativa para actos de competencia del pleno. El precepto establece la necesidad de que esa iniciativa surja formalmente por un comité compuesto por, al menos, 20 personas que formularán una propuesta dirigida a la Secretaría General del ayuntamiento. Tras superar una fase de verificación ante el órgano competente por materia, el comité dispone de un plazo de 3 meses para recoger, por los menos, 2000 firmas de adhesión. Superada también esta fase y otros trámites preparatorios, la propuesta debe ser incluida en el orden del día del Pleno municipal en un plazo no superior a los 90 días desde su depósito.

\subsection{Los órganos municipales de consultación: las «consulte»}

Numerosos ayuntamientos han dado implementación al mandato legal contenido en el Art. 8 del «Testo unico delle leggi sull'ordinamento degli enti locali» a través de la creación de las que, en italiano, se definen «consulte». Se trata de órganos de participación previstos en los estatutos municipales cuya intervención, en determinados ámbitos específicos, puede ser facultativa u obligatoria. Su composición suele ser mixta, es decir, pueden incluir representantes de asociaciones inscritas en registros municipales creados ad hoc, pero también ciudadanos particularmente competentes en el ámbito de interés. Su función suele ser consultiva y propositiva, y aunque el requerimiento de su labor pueda ser configurado por los estatutos como obligatorio, normalmente sus dictámenes no suelen ser vinculantes, si bien es cierto que cualquier decisión contraria a los actos consultivos o propositivos de las «consulte» debería acarrear algún coste político para quién la adopte.

Normalmente los ayuntamientos que adoptan el mecanismo de estos órganos consultivos instituyen también listados de asociaciones reconocidas que pueden ser llamadas a participar en las labores consultivas cuando cumplan con determinados requisitos o características (por ej., no tener fines lucrativos) y perseguir la defensa de intereses difusos o colectivos. Asimismo, los ayuntamientos se comprometen a favorecerlas, considerándolas sujetos preferentes en las interlocuciones relativas a la programación de la agenda política anual o plurianual y/o atribuyéndoles la concesión para la gestión de determinados servicios municipales (Di Marco, 2014, 8 y 9) ${ }^{36}$.

${ }^{36}$ Veamos, por ejemplo, como se articula, en dos casos distintos referidos a dos ciudades representativas del norte y del sur de Italia (Bologna y Catania), la regulación de las «consulte», sus respectivos estatutos y su concreto funcionamiento a la luz de la documentación disponible en línea. 


\subsection{Referéndums municipales y otras «formas de consultación»}

Otros instrumentos de participación que destacan en el marco del D.Lgs. $267 / 2000$ y que ya habían sido introducidos a través de la Ley 142/1990, son los referéndums locales.

Según establece el Art. 8.4 TUEL estas iniciativas constituyen un contenido «eventual» de los estatutos municipales $\mathrm{y}$-al igual que otras formas de

En virtud del Art. 8 del Estatuto de la ciudad metropolitana de Bologna (aprobado por la conferencia metropolitana de Bologna del 23 de diciembre de 2014) por el que se regulan los mecanismos de participación, el pleno municipal instituye órganos de consultación «temáticos permanentes para facilitar la agregación de intereses difusos y para garantizar la expresión de exigencias de grupos sociales». El Art. 2 del Reglamento de las «consulte» establece que las mismas son «oídas en ocasión de la elaboración de actos de gobierno de particular interés social o de medidas que conciernan a la constitución de servicios en el territorio». Las labores de esos órganos pueden ser encargadas por el alcalde, por la junta de gobierno local o por el pleno municipal o pueden actuar por iniciativa propia. Además, existe la posibilidad para las distintas áreas de gobierno («commissioni») de convocar sesiones cognoscitivas para percatarse de la opinión de las «consulte» en los respectivos ámbitos de competencia. Según el Art. 5 pueden formar parte de esos órganos consultivos «las asociaciones libres inscritas en un registro municipal, las asociaciones, los sujetos del tercer sector y los grupos sociales».

Actualmente, la ciudad de Bologna cuenta con las siguientes «consulte» temáticas: de asociaciones familiares; de lucha contra la exclusión social; para la superación de la discapacidad; de deportes; de «la bicicleta»; para la protección de los animales y los hábitats. Un análisis sumario de la documentación disponible en línea (Iperbole, 2021b) nos sirve para constatar que las «consulte» más activas y productivas son las que atañen a la viabilidad urbana en bicicleta y las que se preocupan del bienestar animal. Sin embargo, el resto de las "consulte» publican actas que se remontan al año 2018 con un contenido escueto o casi nulo.

Por su parte, el Estatuto de la ciudad de Catania (aprobado por su pleno en la sesión de 10 de mayo de 1995) instituye las «consulte» en su Art. 61, determinando que las componen miembros, con un mandato de 4 años, nombrados por el alcalde y designados por entidades o asociaciones ciudadanas, por organizaciones sindicales o de categoría que actúan en los sectores de interés de las «consulte» mismas. Sus funciones consisten en concurrir a la programación de las intervenciones en esos distintos sectores. La labor de sus miembros no es retribuida. En virtud del Art. 62, el ayuntamiento de Catania establece la "consulta municipale dei giovani» como órgano de estudio de las problemáticas juveniles y para la formulación de propuestas en mérito. Su composición es mixta prevé la inclusión de expertos de la materia y de representantes de las asociaciones presentes en el territorio. Asimismo, (Art. 62.3) se instituye la "consulta dell'economía e del lavoro» como órgano de asesoramiento de la junta de gobierno local. Por último, el Estatuto prevé la constitución de otras «consulte», es decir: «para la integración de los discapacitados»; «para la igualdad de oportunidades»; «para los problemas de los extracomunitarios»; «para los problemas y la convivencia con los animales», etc.

Visitando la página web del ayuntamiento de Catania es posible recuperar informaciones exclusivamente sobre la «consulta municipale dei giovani», el reglamento de su funcionamiento y algunos datos relativos a la renovación del órgano (Comune di Catania, 2021). 
consultación de la ciudadanía - deben interesar materias de exclusiva competencia local, pues se trata de evitar que esos instrumentos puedan concernir a fines que trasciendan el propio ámbito territorial. Ese mismo precepto, por otra parte, establece que la celebración de esas consultaciones o referéndums no puede coincidir con otras operaciones electorales de interés provincial, municipal o de circunscripción. La razón de esto consiste en garantizar la libertad de voto y en evitar, en la medida de lo posible, que los actores políticos locales puedan tener un peso decisivo en los resultados finales de dichas consultaciones (Vandelli, 1991, 109).

La autonomía estatutaria municipal incide de modo variado en las condiciones o presupuestos para la celebración de los referéndums, en lo que atañe a los sujetos que puedan iniciarlos y participar en ellos y en la trascendencia política de sus resultados.

Limitando nuestro análisis a las distintas tipologías de convocatorias referendarias, es posible indicar que la forma más frecuentemente utilizada por los ayuntamientos italianos es la «consultiva» ${ }^{37}$. Esta clase de referéndums viene en consideración en relación con actos que la administración pública entiende adoptar —o que ya ha adoptado - con el fin de conocer la opinión de la comunidad territorial al respecto ${ }^{38}$. En lo que atañe a su promoción, el tenor literal del Art. 8 TUEL — «pueden ser, además, previstos referéndums también bajo requerimiento de un número adecuado de ciudadanos»parece sugerir que la entidad llamada a convocar normalmente esta tipología de instrumentos es la autoridad pública local y, alternativamente, la colectividad $^{39}$. La autonomía estatutaria de los ayuntamientos disciplina los efectos de estos referéndums de una forma muy diversa. En términos generales es

${ }^{37}$ Probablemente debido a que esa modalidad de consultación referendaria, originariamente y hasta la reforma parcial introducida por el Art. 3.1 de la citada Ley 265/1999, de 3 de agosto, constituía la única posible (Conte, 2015, 89).

38 Así, por ejemplo, el Art. 49 del Estatuto municipal de Catania (Comune di Catania, 1995) señala que los referéndums de este tipo representan instrumentos útiles para orientar el criterio de la administración en relación con las «decisiones que conciernen al territorio, a la vida económica, social y cultural de la comunidad».

39 Conte a este respecto señala que existe una diferencia importante entre los referéndums que han sido convocados por la población y los que lo han sido por las autoridades: en este último caso, el referéndum constituye una apuesta de la administración local que aspira a compartir responsabilidades con la ciudadanía respecto de una decisión controvertida. Sin embargo, los referéndums convocados directamente por la ciudadanía constituirían una expresión más auténtica de voluntad de participación $(2015,91)$.

Para el Art. 49 del Estatuto municipal de Catania (Comune di Catania, 1995), citado anteriormente, los referéndums consultivos pueden ser promovidos por 3 consejos de circunscripción con deliberación aprobada por mayoría absoluta de sus miembros; por el $3 \%$ de los ciudadanos inscritos en el censo municipal, con adhesiones recogidas en un plazo de 3 meses; o por el pleno municipal. 
posible afirmar que los resultados de convocatorias no suelen producir consecuencias jurídicas obligatorias para los órganos políticos locales ${ }^{40}$.

Los referéndums de tipo consultivo no constituyen la única categoría descrita y regulada en los estatutos municipales italianos. Junto con ellos, encontramos convocatorias cuya eficacia y naturaleza difieren ampliamente.

Así, se definen «referéndums deliberativos» aquellos instrumentos referendarios que no se limitan a indagar el juicio de la opinión pública para determinar el criterio de las autoridades políticas, sino que son idóneos para producir efectos jurídicos inmediatos y directos ${ }^{41}$. Esta tipología de referéndum —en la que recaen también los llamados «referéndums abrogativos»por sus características intrínsecas, suele exigir un quorum de participación ${ }^{42}$.

Por otra parte, algunos estatutos municipales regulan referéndums de tipo «confirmativo». Se trata de consultaciones que tienen lugar en la fase que transcurre entre la adopción de una deliberación y la entrada en vigor de esta. Sus efectos pueden ser diversos: vinculantes o meramente consultivos. En el

Sin embargo, el ayuntamiento de Bologna (Arts. 10-22 del «Regolamento sui diritti di partecipazione e di informazione dei cittadini», Iperbole, 2021a) establece que 200 electores inscritos en el censo municipal pueden solicitar al alcalde la convocatoria de un referéndum consultivo.

${ }^{40}$ Así, por ejemplo, el Regolamento del ayuntamiento de Bologna no prevé ningún quorum participativo para una celebración referendaria que sea válida. Y en relación con los efectos de los resultados, el Art. 22 del Regolamento, de manera escueta, establece que «independientemente del número de ciudadanos que han participado al voto, el pleno municipal, en un plazo de 3 meses desde la proclamación de los resultados, se pronuncia sobre el objeto del referéndum».

Al extremo opuesto encontramos la regulación de los efectos de las convocatorias referendarias de tipo consultivo, propositivo y abrogativo, descritas por el Art. 52 del Estatuto municipal de Catania (Comune di Catania, 1995) por el que la propuesta objeto de consultación se entiende aprobada cuando hayan participado a la votación la mayoría de los titulares del derecho al voto y cuando haya votado favorablemente el 50\% más uno de los participantes. Cuando se den estas condiciones, el pleno municipal deberá, obligatoriamente, discutir el resultado de la convocatoria en un plazo de 30 días desde su publicación. El precepto establece tajantemente que el resultado del referéndum «vincula la administración a dar ejecución a la voluntad popular expresada en la consultación».

${ }^{41}$ Un ejemplo de ello es el Art. 91.4 del Estatuto de Enna (Comune di Enna, 2011) por el que «la aprobación de un referéndum abrogativo determina la abrogación de la deliberación a partir del día siguiente a la proclamación del resultado referendario»: se trata de un efecto que se produce automáticamente, sin que sea necesaria la intervención de las autoridades locales para dar ejecución a la voluntad popular expresada con el voto. Las diferencias con el citado Art. 52 del Estatuto municipal de Catania (Comune di Catania, 1995) son evidentes.

${ }^{42}$ Efectivamente, siguiendo el ejemplo del Estatuto de Enna, el Art. 91.13 y 14 (Comune di Enna, 2011) establece que «el referéndum es válido si han participado a la consultación la mitad más uno de los electores» y que «la propuesta referendaria es aprobada si logra la mitad más uno de los votos válidos». 
primer caso, si la propuesta es contraria al acto adoptado por las autoridades locales, los efectos que se generan se definen «opositivos», pues precluyen la entrada en vigor de dicho acto. Según indica Conte, esta categoría de referéndums puede considerarse «eventual» dato que su convocatoria queda en la disponibilidad de una fracción del cuerpo electoral, de los órganos políticos locales o de una minoría de ellos $(2015,95)$.

Igualmente, es posible hablar de «referéndums suspensivos» —o con eficacia suspensiva - en relación con esos instrumentos referendarios que generan esa clase de efectos sobre los actos políticos adoptados por las autoridades públicas desde el momento en que el referéndum ha sido válidamente convocado, con independencia de los resultados que se lograrán una vez que la ciudadanía se haya pronunciado sobre la propuesta.

Por último, cabe señar la existencia de los «referéndums propositivos», es decir, convocatorias cuyo objetivo consiste en formular propuestas para la adopción de normas estatutarias o reglamentarias o de actos administrativos generales ${ }^{43}$.

El Art. 8.3 del D.Lgs. 267/2000 indica, además, que en los estatutos municipales «deben estar previstas formas de consultación de la población». Esa fórmula plantea dudas interpretativas: ¿se trata de una expresión genérica que incluye y engloba también a los referéndums o de una referencia que el legislador italiano hace a instrumentos distintos de los que se hallan enumerados en ese precepto?

De aceptar esa primera lectura, se debería concluir que los referéndums no constituyen un contenido «eventual» de los estatutos, sino unas previsiones obligatorias y básicas que deben formar parte de la regulación de todo ayuntamiento italiano.

De ser válida la segunda interpretación, nos encontraríamos ante la circunstancia opuesta, por lo que la locución «formas de consultación» tendría la naturaleza de cláusula abierta concerniente a instrumentos intrínsecamente distintos de los de tipo referendario.

Para Conte $(2015,77)$ la diferencia podría pues residir en lo siguiente: «las formas» a la que alude el Art. 8.3 TUEL harían referencia a iniciativas impulsadas por los poderes políticos locales, mientras que la promoción de los referéndums debería recaer principalmente en la disponibilidad de la ciudadanía.

Para Zucchetti (2000, 86), sin embargo, la contraposición se jugaría sobre el terreno de los efectos: «las formas» consistirían básicamente en encuestas de opinión realizadas para conocer el sentir de la comunidad, mientras que los referéndums representarían instrumentos con una mayor o menor trascendencia política, en función de cómo se module su eficacia vinculante.

${ }^{43}$ Véase Art. 42.5 Estatuto de la ciudad de Bari. 
Indudablemente, la fórmula literal del Art. 8.3 TUEL no es de las más afortunadas y no contribuye a esclarecer, de manera unívoca, su contenido y alcance. No obstante, la introducción de un deber de previsión en los estatutos municipales de formas de consultación ulteriores respecto a los referéndums encuentra explicación a través de una interpretación sistemática del precepto en el contexto integral del TUEL. Lo cierto es que el legislador italiano desea que las administraciones locales consulten a la población, no solo a través de convocatorias referendarias, sino también a través de otros mecanismos («formas»), en principio indefinidos y en los que la autonomía municipal encuentra libre expresión. Si la creación y articulación de esos mecanismos es consecuencia de la discrecionalidad política de los poderes locales, no se aprecia la razón por la que su efectiva promoción e implementación no pueda recaer también en la disponibilidad de la ciudadanía: si lo normal es que sea la administración pública la que solicite el criterio de la ciudadanía, nada excluye - en teoría - que este mismo proceso pueda desarrollarse al revés, siendo la ciudadanía la que adopte la iniciativa de ofrecer su valoración acerca de la oportunidad de adoptar un acto o no hacerlo. Ahora bien, en lo que atañe a los efectos de esas «formas libres», cabe recordar que su función es la de instrumentos de consulta, de modo que compete a las administraciones locales adoptar las decisiones finales y, por lo tanto, asumir todas las consecuencias que de ellas puedan derivar.

\section{CONSIDERACIONES CONCLUSIVAS: EDUCAR PARA LA PARTICIPACIÓN}

El análisis realizado hasta aquí pone en evidencia un dato incuestionable: ya a partir de la Ley 142/1990 — y hoy con el TUEL — el legislador italiano ha querido dibujar un panorama completo de instrumentos participativos potencialmente útiles para permitir una implicación efectiva de la ciudadanía en la política local.

$\mathrm{Y}$, sin embargo, los datos de participación más recientes, y otros elementos sobre los que merece la pena reflexionar en estas conclusiones, nos devuelven la imagen de una realidad distinta, en la que la mera previsión de esos instrumentos participativos e incluso su inclusión coactiva en los estatutos municipales, no parece garantizar, a priori, que su aplicación e implementación sean reales y efectivas.

Hoy, al igual que en el pasado, eso se debe a una serie de razones o causas que ahondan sus raíces en terrenos diversos.

1. Tal vez sea ocioso recordar que «participar» significa, literalmente, «tomar parte», «involucrarse en primera persona». En el contexto de la política local, el verbo "participar» supone la voluntad y la 
posibilidad de que sujetos terceros - la ciudadanía - puedan intervenir en esos procesos en los que se articula la gestión de la cosa pública local, unos procesos que han constituido - desde siempre - un territorio reservado a los actores políticos tradicionales. Por eso mismo debemos ser conscientes de que hablar de participación política significa hablar de una pugna por el poder, de un poder que en teoría el legislador imagina repartido - en cuotas no necesariamente idénticas - entre administración, por una parte, y administrados, por otra. $\mathrm{Y}$, sin embargo, cabría recordar que la aprobación de una norma - llámese TUEL o estatuto municipal- o la inclusión de una previsión legal útil para abrir espacios de participación no supone, de primeras, un cambio inmediato en la realidad política y una efectiva apertura de esos espacios participativos imaginados en un principio. Es preciso reflexionar sobre la sincera disposición de esos actores políticos tradicionales a ceder cuotas de poder con el fin de aplicar, concreta y efectivamente, el dictado normativo contenido en el TUEL. Desde luego, investigar en el alma de los poderes públicos locales constituye un reto de indudable dificultad.

2. En las primeras etapas de la historia constitucional de la República italiana, el legislador tarda en dar ejecución al principio de autonomía de las entidades locales. Tarda, por su incapacidad de abandonar los esquemas jerárquicos de organización del Estado y por ese temor - heredado del pasado - que interpreta la autonomía como una amenaza al principio de unidad de la Nación.

Por razones no solo políticas, sino también económicas y culturales, es solo a partir de los años 70 cuando se supera la lógica tradicional por la que la ciudadanía debe intervenir solo en correspondencia de las convocatorias electorales y no necesita ser «molestada» con llamamientos aleatorios a la participación. Sin embargo, en esta misma fase, no resultan todavía claros y definidos los límites que separan las nociones de participación y de consulta. Quién se preocupa de intervenir, animado por una atmósfera política y cultural entusiasmada e intensa, que cuestiona y crítica con pasión los esquemas del pasado, lo hace sin comprender del todo que su papel, y el de la ciudadanía, es de mero actor secundario: sujetos llamados a fiscalizar - a posteriorila actuación de los poderes políticos locales o llamados a ser consultados cuando $-\mathrm{y}$ si- esos mismos poderes lo estimen oportuno. Por otra parte, cuando a través de artificios normativos se construyen y abren espacios de consultación estables, esos mismos espacios pronto se ven ocupados por representantes de los partidos políticos tradicionales. De este modo, incluso en estos órganos de consulta, se reproducen las mismas dinámicas ya presentes en las asambleas municipales 
y se expresan ideas, votos y resoluciones adoptadas en un sentido sectario y partidista. Todas estas circunstancias concurren inevitablemente a ensanchar el distanciamiento entre personas e instituciones.

3. A partir de los años ' 90 el legislador italiano es protagonista de un fervor normativo que, en el ámbito de la autonomía local, se traduce en la aprobación de la Ley 142/1990 y en la creación de los estatutos municipales en los que no pueden faltar previsiones, normas y mecanismos legales dirigidos a impulsar la participación ciudadana en la política local. Todo eso confluye en el D.Lgs. 267/2000, con el que finalmente Italia se dota de un Texto Único sobre el Ordenamiento de las Entidades Locales. Con esos cambios normativos ipuede considerarse zanjada la cuestión participativa en ámbito municipal? La respuesta es no. En un estudio que la Asociación Nacional de Municipios Italianos (ANCI, 2005) realizó con una cierta distancia en años desde la reforma impulsada por la Ley 142/1990, se indicaba que el $56 \%$ de los italianos no estaba al corriente de que su ayuntamiento tenía un estatuto, aunque un $93 \%$ de los entrevistados considerara «muy importante o bastante importante» que la administración local se preocupara de dar a conocer ese documento y explicar con suficiente claridad su contenido ${ }^{44}$.

Cabría preguntarse cómo puede lograrse esa tan «deseada» participación de la ciudadanía en la administración política local, si los instrumentos llamados a hacerla posible quedan del todo ocultos en las penumbras de los textos estatutarios. En una lógica que recuerda al «Gattopardo» de Tomasi di Lampedusa: los cambios que se producen en este ámbito de la política parecen dirigidos a permitir que las dinámicas dominantes permanezcan inmutadas.

4. En las primeras páginas de este estudio hemos puesto en evidencia que la política local es, por definición, esa dimensión del poder que el ciudadano siente - o debería sentir - como más cercana y capaz de influir en su calidad de vida, en lo colectivo y en lo cotidiano. Sin embargo, si esta cercanía es meramente simbólica porque, en el fondo, los centros de poder local se siguen percibiendo como ajenos e inalcanzables, no nos debe sorprender si, en términos generales, la fractura existente entre la ciudadanía y la política es cada vez más profunda y amplia. Así lo corroboran algunos datos recientes elaborados por el Instituto Nacional de Estadística (INSTAT, 2020a) que indican cómo entre el 2014 y el 2019, el porcentaje de personas

${ }^{44}$ Una situación que Di Marco $(2014,6)$ describe como «democracia escondida», una democracia que en premisa podría y debería existir, pero que nadie se preocupa dar a conocer y, por ende, de realizar en un sentido efectivo, real y concreto. 
mayores de 14 años que no participan en la vida política se ha ido incrementando de un $19 \%$ a un $23,2 \%$, de modo que más de 12 millones de italianos no hablan, no se informan, ni participan directamente en este aspecto fundamental de la vida en comunidad. Particularmente dramático es el dato relativo a la «participación política indirecta»si consideramos que, actualmente, más de $1 / 4$ de la población italiana declara no informarse «jamás» de cuestiones relacionadas con la actualidad política en general por desinterés o desconfianza.

\section{Interés por la política}

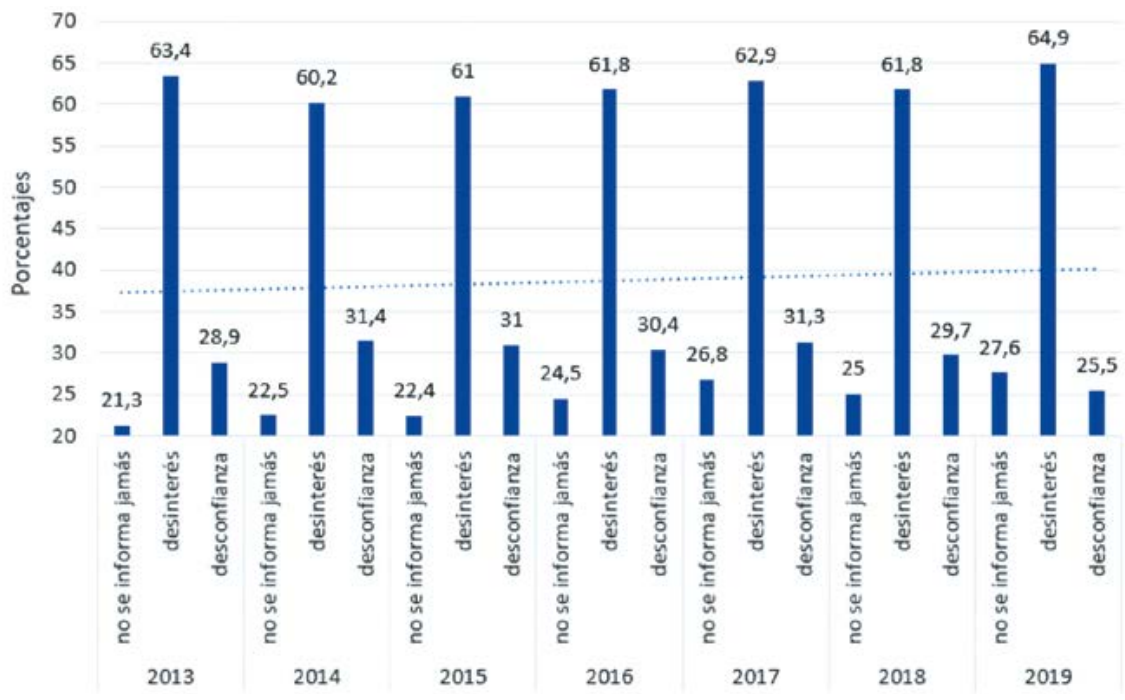

De este modo, no nos deben sorprender noticias como las que nos llegan incluso de localidades con un tamaño reducido, en las que el sentimiento de pertenencia y participación debería ser mayor: el 2 de febrero de 2021 el pleno municipal de la isla de Pantelleria aprueba un reglamento para la celebración de referéndums locales (Marrucci, 2021). Para que esos instrumentos puedan ser efectivos es necesario constituir un Comité de garantía compuesto por el secretario municipal y dos representantes (uno de mayoría y otro de minoría) a escoger de un listado de ciudadanos dispuestos a desarrollar voluntariamente esa función cuando quiera que sea necesario. Y, sin embargo, dos convocatorias públicas, celebradas en marzo y mayo, fracasan en el intento de constituir ese simple listado de voluntarios. La frustración 
del alcalde se ha manifestado con estas palabras: «Lamentamos profundamente que, debido a este fallo, la ciudadanía no pueda ejercer su derecho a participar. Hemos puesto a su disposición una herramienta que prometimos en la campaña electoral y que queda inutilizada por la falta de participación de quienes podrían garantizar que la participación se ejerciera efectivamente.» Desde luego, no deja de ser paradójico que ese «fallo» denunciado por el alcalde y que impide la participación de la ciudadanía se deba, esencialmente, al desinterés de esa misma.

Así, datos como los del ISTAT y ejemplos como los de Pantelleria, nos deben servir para recordar que todo lo que rodea la participación política representa un problema complejo y que sus reflejos cambian en función de las perspectivas que queramos adoptar. De este modo, si es cierto que una serie de responsabilidades graves recaen en esos actores que ejercen la representación, detentan el poder y no advierten la necesidad de dar efectividad a esos espacios de participación previstos en las leyes; también es cierto que aquellos que están representados, que no ejercen directamente el poder y deberían sentir la importancia de participar e involucrarse, no siempre perciben esa necesidad con la pasión y la intensidad que sería deseable en un contexto democrático.

No debemos llamarnos a engaño: el desinterés de la ciudadanía por la política pública no es un problema reciente. En «Los Acarnienses», una comedia de Aristófanes del 425 a.C., cuando Lámaco defiende sus razones argumentando haber sido elegido por la asamblea, Diceópolis se burla de él, afirmando que a esa votación habían participado solo «tres cucos». Y en efecto, no es ocioso recordar que en la Atenas del siglo IV a.C., los esclavos escitas estaban encargados de empujar hacia el ágora, con cuerdas teñida de rojo, a los atenienses llamados a participar en la Eclesia. Y aquél, cuya ropa quedara manchada de rojo, sufría luego el pago de una sanción, pues la participación constituía un deber insoslayable.

Que la cultura helenística tuviera clara la gravedad del pecado de la indiferencia hacia los asuntos públicos, queda demostrado incluso por Tucídides que, relatando el célebre discurso fúnebre pronunciado por Pericles, afirmaba: «sólo nosotros juzgamos al que no se cuida de la república, no solamente por ciudadano ocioso y negligente, sino tam-

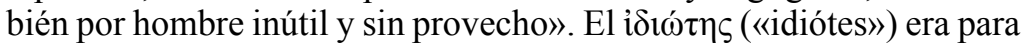
los griegos aquel individuo preocupado solo de sus asuntos privados, exclusivamente centrado en sus intereses particulares, indiferente a los asuntos públicos y del todo ajeno a la formación de la voluntad común (Milione, 2021, 10). 
5. La evolución legislativa que la materia objeto de nuestro estudio ha experimentado en Italia en estos últimos 50 años demuestra ampliamente que no es suficiente reconocer espacios potenciales de participación si esos mismos no llegan a ser efectivos y concretos. Por otra parte, no basta con abrir a la ciudadanía las puertas de la participación, si la ciudadanía no está realmente dispuesta a cruzar esos umbrales. ¿De qué sirve incluir instrumentos participativos en los estatutos municipales si nadie los conoce o se preocupa de ejecutarlos?

$\mathrm{Y}$, sin embargo, estas últimas consideraciones nos conducen a una reflexión posterior y final: el debate en torno al problema de la participación política local no debería desarrollarse - como frecuentemente ha ocurrido en el pasadodesde una mera perspectiva binaria, que se reduce a un análisis costes-beneficios de las lógicas participativas. Los extremos del problema no residen exclusivamente en las dos alternativas que consisten en «permitir» $\mathrm{o}$ «denegar» la participación de la ciudadanía. Existe, en realidad, un aspecto más profundo y primordial, que no puede ser olvidado porque atañe a la participación en todos los ámbitos en los que se produce: el que atañe a la «cualidad» de la misma.

La historia de la Humanidad está repleta de ejemplos en los que la ciudadanía, llamada a deliberar sobre asuntos candentes, oportunamente manipulada por rétores o demagogos, ha decidido adoptar las soluciones menos favorables para sus propios intereses. Debería servirnos de consuelo el mero hecho de pensar que, si se trata de decisiones malas, adoptadas a nivel local, las repercusiones de estas no podrán sino tener un mismo alcance, un alcance local. Y, sin embargo, esas singulares consultaciones populares narradas por los Evangelistas en el juicio a Cristo o por Platón en la Apología de Sócrates, vienen a despojarnos también de ese efímero consuelo.

En conclusión, para que la participación de la ciudadanía en la política funcione a cualquier nivel y en cualquier contexto nacional que aspire a ser genuinamente democrático - Italia inclusa - es necesario, en primer lugar, educar a la ciudadanía: educarla a interesarse por la dimensión colectiva de la existencia, a informarse en un sentido crítico, a reivindicar espacios de participación por el hecho mismo de sentir la irrenunciable necesidad de contribuir a la gestión de la cosa común.

Para lograr este objetivo, no es suficiente con obligar a todas las entidades locales italianas a incluir en sus estatutos cláusulas participativas. Hacer esto es indudablemente más sencillo que apostar por un modelo educativo que fomente el interés por la política y la capacidad de análisis crítica de quienes, un día, tendrán que adoptar decisiones colectivas. Participar, decidir y actuar como personas libres, a sabiendas de que «la libertad no es vivir en la copa de un árbol, no es ni siquiera el vuelo de un moscón, no es un espacio libre, la libertad es participación». 
Palabras estas que Giorgio Gaber cantaba en una Italia de hace años, en una Italia que todavía creía en la política como forma de realización de las utopías.

\section{REFERENCIAS BIBLIOGRÁFICAS EMPLEADAS}

ANCI (2005). City democracy: dagli statuti alla partecipazione: gli italiani e la democrazia comunale, le attese e le preferenze dei cittadini.

BARRESI, Roberto (1994). «Gli istituti di partecipazione, tra pubblico e privato, nell' ordinamento locale (la L. 142 dell' 8 giugno 1990 alla luce dei principi della L. 241 del 7 agosto 1990)». Rivista amministrativa della Repubblica Italiana, Vol. 145 - n. ${ }^{\circ}$ 10/11: 1156-1180.

BENVENUTI, Feliciano (1968). «Mito e realtà nell'ordinamento amministrativo italiano». En Atti del Congresso celebrativo del centenario delle leggi di unificazione amministrativa. Coordinado por Giovanni Miele, 65 y ss. Roma: Neri Pozza Editore.

Berti, Giorgio (1975a). «Art. 5». En Commentario alla Costituzione. Dirigido por Giuseppe BrancA, 286 y ss. Bologna-Roma: Zanichelli.

- (1975b). «Decentramento urbano e partecipazione». Amministrare, 2.

Calvano, Roberta (2018). «L'art. 5, tra promozione e compressione del principio autonomista: un'altalena collegata all'involuzione del sistema politico italiano. Recensione a "Costituzione italiana: Art. 5" di Sandro Staiano, (Carocci, 2017, Roma)». Federalismi.it: Rivista di Diritto pubblico italiano, comparato, europeo, 10: 1-8.

Ceccarelli, Francesco y Maria Angiola Gallingani (1987). Bologna: decentramento, quartieri, città 1945-1974. Bologna: Istituto per la storia di Bologna.

Cerchia, Giovanni (2005). «Claudio Petruccioli, intervistato da Giovanni Cerchia». En La crisi del sistema politico italiano e il Sessantotto, coordinado por Gaetano QuAgLiariello y Giovanni Orsina. Roma: Rubbettino.

Comune di Catania (1995). «Statuto della Cittá di Catania». Amministrazione Trasparente Disposizioni generali Statuti e leggi regionali. Acceso el 31 de octubre de 2021, https://www.comune.catania.it/trasparenza/download.aspx?Attachment=Pr/ QF4vET0srAsA9elrdqYUJmUYEDpW3nkaLF0pTJEgFJqluJldn/tcnLIWDaNhPk5fmnCl6xpyLd9U-NHdybpBbK-zAWiI5CtghbapFTNjDfUiymL/t5Htxa$\mathrm{X} 8 \mathrm{~A} 5 \mathrm{sg} /$.

Comune di Catania (2021). «Consulta giovanile». Attività Parascolastiche Pari Opportunità Politiche Giovanili. Acceso el 25 de octubre de 2021, https://www. comune.catania.it/il-comune/uffici/istruzione/attivit-parascolastiche/consultagiovanile.aspx.

Comune Di ENNA (2011). «Statuto comunale». Enna rete civica. Acceso el 01 de noviembre de 2021, https:/www.comune.enna.it/index.php/statuto-comunale-l.

CONTE, Francesco (2015). «La partecipazione popolare nell'esperienza dei referendum comunali». Tesis doctoral. Università di Bologna. DOI: 10.6092/UNIBO/ AMSDOTTORATO/7018.

De Tocqueville, Alexis (1835-40). La democracia en América. (Aguilar: Madrid, 1989). 
Di MARCO, Carlo (2014). «Democrazia partecipativa, ordinamenti locali e pratiche deliberative». Corsi per facilitatori 2014. Acceso el 21 de octubre de 2021, http:// www.comune.bussisultirino.pe.it/uploads/plugin_html/Democrazia-partecipativa-e-ordinamenti-locali.pdf.

FENZI, Enrico (2020). «Una traccia attraverso la poesia política da Guittone a Petrarca». En Al di là del Repubblicanesimo Modernità politica e origini dello Stato, coordinado por Guido CAPPELLI. Napoli: UniorPress.

Ferreira Fernández, Antonio Javier (2016). «La Carta Europea de Autonomía Local: orígenes y perspectivas». Dereito: Revista xuridica da Universidade de Santiago de Compostela, $n .^{\circ}$ Extra-1: 13-20.

Giallongo, Angela (2018). «Alcune riflessioni sulle emozioni del Movimento Studentesco: Italia 1968». En Globalizing the student rebellion in the long '68, dirigido por Andrés PAYÁ Rico et alii. Salamanca: FahrenHouse.

GIUSEPPONI, Katia (2009). Gestione e controllo delle amministrazioni pubbliche. Strumenti operativi e percorsi d'innovazione. Milano: Giuffrè.

IPERBOLE (2021a). «Regolamento sui diritti di partecipazione e di informazione dei cittadini». Rete civica del Comune di Bologna. Acceso el 31 de octubre de 2021, https://www.comune.bologna.it/regolamenti/regolamento-diritti-partecipazioneinformazione-cittadini.

- (2021b). «Consulte comuniali». Rete civica del Comune di Bologna. Acceso el 25 de octubre de 2021, https://www.comune.bologna.it/servizi-informazioni/ consulte-comunali.

IsMEL (Istituto per la memoria e la cultura del lavoro). s.f. Torino e le fabbriche. Percorsi multimediali sulla storia industriale della città. Torino: Centro online storia e cultura dell'industria.

ISTAT (2020a). «La partecipazione política en Italia». Acceso el 05 de noviembre de 2021, https://www.istat.it/it/files//2020/06/REPORT_PARTECIPAZIONE_POLITICA.pdf.

- (2020b). «Informazione politica — età dettaglio». Aspetti della vita quotidiana. Acceso el 05 de noviembre de 2021, http://dati.istat.it/.

LASAgABASTER Herrarte, Iñaki (2007). La carta europea de la autonomía local. Madrid: Iustel.

LUCIANI, Massimo (2008). «Il referendum. Questioni teoriche e dell'esperienza italiana». Revista catalana de dret pùblic, n. ${ }^{\circ}$ 37: 157-182.

LuCIFREDI Roberto y Giuseppe ColeTti (1956). Decentramento amministrativo. Commento della Legge di delega 11 marzo 1953, n. 150, e dei Decreti legislativi delegati. Torino: Utet.

LuCIFREDI, Roberto (1960). «Decentramento amministrativo». Novissimo Digesto ltaliano, Vol. V.

MARrUCCI, Francesca (2021). «Pantelleria: non si trovano Garanti per i Referendum Comunali. Parla il Presidente Vallini». Pantelleria notizie, 23 agosto 2021. Acceso el 05 de noviembre de 2021, https:/www.pantellerianotizie.it/2021/08/23/ pantelleria-non-si-trovano-garanti-per-i-referendum-comunali-parla-il-presidente-vallini/.

Merloni, Francesco (2010). «La Carta Europea de la Autonomía local y su recepción en Italia y España». Anuario del Gobierno Local, n. ${ }^{\circ}$ 1: 489-519. 
Milione, Ciro (2021). «El derecho a la educación como fundamento de la democracia y premisa para el libre desarrollo de la personalidad». Revista de Educación y Derecho, n. ${ }^{\circ} 24: 1-33$.

Ministero Dell'InTERno (2021). «Elezioni Amministrative del 3 e 4 ottobre 2021». Acceso el 10 de octubre de 2021, https://www.interno.gov.it/it/speciali/elezioni-2021.

Moвılo, Giuseppe (2017). Le città metropolitane. Dimensione costituzionale e attuazione statutaria. Torino: G. Giappichelli Ed.

Ortega Álvarez, Luis Ignacio (1993). «La Carta Europea de la autonomía local y el ordenamiento local español». Revista de estudios de la administración local y autonómica, n. ${ }^{\circ}$ 259: 475-498.

PAstori, Giorgio (1962). "Gli enti comunitari». Archivio dell'Istituto per la Scienza dell'Amministrazione Pubblica, $\mathrm{n}^{\circ}{ }^{\mathrm{1}} 1$.

PAtroni Griffi, Giuseppe. 2011. «Procedimento amministrativo e responsabilizzazione dei poteri pubblici: a vent'anni dalla legge n. 241/1990». Corriere giuridico, Vol. $28-$ n. $^{\text {o }}$ 3: 301-309.

PINTO, Ferdinando (2017). «La disciplina del procedimento amministrativo a quasi trent'anni dall'approvazione della Legge n. 241 del 1990». Amministrativamente. Rivista trimestrale di diritto amministrativo, $\mathrm{n}^{\circ}$ 11-12.

RESTA, Domenico (1992). «Il 'vero' volto della riforma del procedimento amministrativo attuato ai sensi della legge 7 agosto 1990 n. 241». Rivista amministrativa della Repubblica Italiana, Vol. 143 — n. ${ }^{\circ} 10$ : 1407-1416.

Rolla, Giancarlo, Tania GropPi y Lorenzo LuATti (1990). L'Ordinamento dei comuni e delle provincie. Milano: Giuffrè.

SCAFOLETTI, Marcella (2004). «Appunti sulla legge di riforma del procedimento amministrativo 7.8.1990, n. 241 e successive modifiche». Il nuovo diritto, Vol. 81 - n. ${ }^{\circ} 11$.

Staderini, Francesco (1986). Diritto degli enti locali. Padova: CEDAM.

VANDELli, Luciano (1991). Ordinamento delle autonomie locali. Commento alle legge 8 giugno 1990, n. 142, Rimini: Maggioli.

VANDELli, Luciano (2015). Il sistema delle autonomie locali. Bologna: Il Mulino.

VESPERINI, Giulio (2010). «La legge sulle autonomie locali venti anni dopo». Rivista trimestrale di diritto pubblico, n. $^{\circ}$ 4, ottobre/dicembre: 953-980.

ZACChINI, Bruna (1976). Dieci anni di decentramento a Bologna. Bologna: Edizioni Luigi Parma.

ZucchetTi, Alberto (2000). «Articolo 8». En Testo unico degli enti locali, Vol. 1, coordinado por Vittorio Italia. Milano: Giuffré. 


\title{
«LA LIBERTÀ È PARTECIPAZIONE»: LA PARTICIPACIÓN POLÍTICA LOCAL EN ITALIA, ENTRE NORMAS Y REALIDAD
}

\author{
"La libertà è partecipazione": local political participation \\ in Italy, between laws and reality
}

\author{
Ciro Milione \\ Profesor Titular de Derecho Constitucional \\ Facultad de Derecho y CC. EE. y EE. \\ Universidad de Córdoba
}

http://dx.doi.org/10.18543/ed-69(2)-2021pp149-184

\section{Copyright}

Estudios de Deusto es una revista de acceso abierto, lo que significa que es de libre acceso en su integridad. Se permite su lectura, la búsqueda, descarga, distribución y reutilización legal en cualquier tipo de soporte sólo para fines no comerciales, sin la previa autorización del editor o el autor, siempre que la obra original sea debidamente citada y cualquier cambio en el original esté claramente indicado

Estudios de Deusto is an Open Access journal which means that it is free for full access, reading, search, download, distribution, and lawful reuse in any medium only for non-commercial purposes, without prior permission from the Publisher or the author; provided the original work is properly cited and any changes to the original are clearly indicated. 